\title{
Design and Evaluation the Anti-Wear Property of Inorganic Fullerene Tungsten Disulfide as Additive in PAO6 Oil
}

\author{
Wenting Chen ${ }^{1}$, Kunyapat Thummavichai ${ }^{2}$, Xiaorong Chen ${ }^{1}$, Guangsheng Liu ${ }^{1}{ }^{(}$, , Xuefeng Lv ${ }^{1}$, Linyi Zhang ${ }^{1}$, \\ Ding Chen ${ }^{1}$, Santosh Kr. Tiwari ${ }^{1} \mathbb{D}$, Nannan Wang ${ }^{1, *}$ (i) and Yanqiu Zhu ${ }^{1,2, *}$ \\ 1 Key Laboratory of New Processing Technology for Nonferrous Metals and Materials, Ministry of Education, \\ School of Resources, Environment and Materials, Guangxi Institute Fullerene Technology (GIFT), \\ Guangxi University, Nanning 530004, China; chenwt@st.gxu.edu.cn (W.C.); 1814202036@st.gxu.edu.cn (X.C.); \\ Jesson_lgs@st.gxu.edu.cn (G.L.); 1815391020@st.gxu.edu.cn (X.L.); 19142020126@st.gxu.edu.cn (L.Z.); \\ 1914402004@st.gxu.edu.cn (D.C.); ismgraphene@gmail.com (S.K.T.) \\ 2 College of Engineering, Mathematics and Physical Sciences, University of Exeter, Exeter EX4 4QF, UK; \\ kt302@exeter.ac.uk \\ * Correspondence: wangnannan@gxu.edu.cn (N.W.); y.zhu@gxu.edu.cn (Y.Z.)
}

check for updates

Citation: Chen, W.; Thummavichai, K.; Chen, X.; Liu, G.; Lv, X.; Zhang, L.; Chen, D.; Tiwari, S.K.; Wang, N.; Zhu, Y. Design and Evaluation the Anti-Wear Property of Inorganic Fullerene Tungsten Disulfide as Additive in PAO6 Oil. Crystals 2021, 11, 570. https://doi.org/10.3390/ cryst 11050570

Academic Editor: Reshef Tenne

Received: 29 March 2021

Accepted: 13 May 2021

Published: 20 May 2021

Publisher's Note: MDPI stays neutral with regard to jurisdictional claims in published maps and institutional affiliations.

Copyright: (c) 2021 by the authors. Licensee MDPI, Basel, Switzerland. This article is an open access article distributed under the terms and conditions of the Creative Commons Attribution (CC BY) license (https:// creativecommons.org/licenses/by/ $4.0 /)$.

\begin{abstract}
Inorganic fullerene-like tungsten disulfide particles have been proved to have good antifriction and anti-wear properties as lubricating materials. As far as we know, however, when it is used as a lubricant additive, its behavior and action mechanism in the friction process are rarely studied. Herein, IF-WS 2 particles were synthesized by a Chemical Vapor Deposition (CVD) method. The effect of IF-WS 2 particle concentrations in the PAO6 oil on the tribological behaviors was investigated with a four-ball wear machine at both 75 and $100{ }^{\circ} \mathrm{C}$. Additionally, the analyzed morphology and composition of nanomaterials and worn surfaces were analyzed by Scanning electron microscopy (SEM), Transmission Electron Microscopy (TEM) and X-ray photoelectron spectroscopy (XPS). The friction behavior in actual working conditions was studied by a wear testing machine. The experimental results show that compared with the original PAO6 oil, at a dispersion of $0.25 \mathrm{wt} \%$ in PAO6 oil, the IF-WS 2 particles showed the best performance in terms of coefficient of friction, wear scar diameter and wear mass, which significantly reduced by $27 \%$, $43 \%$ and $87 \%$, respectively. At the same time, in the process of friction, it was found that IF-WS particles accumulated in the depressions to fill the scratches, and adsorption films and chemical films, including $\mathrm{FeS}_{2}, \mathrm{WS}_{2}$ and $\mathrm{WO}_{3}$, were formed on the worn surfaces to avoid the direct contact among the friction pairs more effectively, resulting in the improved anti-wear performances. Additionally, the addition of IF-WS 2 particles effectively delayed the rise of lubricating oil temperature. In addition, dispersant span 80 can effectively improve the dispersion and stability of IF-WS 2 in PAO6. This work provides us for understanding the effective lubrication mechanism of IF-WS 2 particles in more detail and having a new acknowledge of the comprehensive performance of IF- $\mathrm{WS}_{2} / \mathrm{PAO} 6$ oil.
\end{abstract}

Keywords: inorganic fullerene; disulfide tungsten; additive; high performance lubricating oil; PAO6; anti-wear

\section{Introduction}

In modern industry, friction and wear are one of the main causes of materials loss, mechanical failure and energy consumption. Lubricants are widely used to counter friction and wear in an effort to reduce energy consumption and improve the durability of machinery [1-4]. Compared with conventional micro-sized additives, the addition of nanoadditives can further improve the performance of lubricating oil in various aspects. Many additives have been developed in recent decades, such as ionic liquids [5-7], nanoparticle additives [8-10], organic ester compounds, etc. [11]. Among them, nanoparticle additives have been widely studied due to their high thermal and chemical stability, as well as excellent mechanical strength. The extremely small size of nanoparticles allows 
them to penetrate contacts of diverse geometries, fill the gaps between contact asperities and ultimately form a protective film under continuous high pressure. The addition of nanoparticles to base oil could significantly enhance the tribological performance of lubricants and offer high capabilities to improve friction, wear resistance, thermal properties, load-carrying capacity and rheological properties [12,13].

Transition metal dichalcogenides, such as molybdenum disulfide and tungsten disulfide, are prone to slip between the crystal sheets due to their unique crystal structure anisotropy, making them an ideal candidate for use as lubricants [9,14-18]. Their unique cage-like structures make the surface of these particles containing little suspended bonds, differing from its $2 \mathrm{H}$ type counterpart so that they have better chemical inertness and will be difficult to adhere to the contact surfaces. Many studies have already shown that using inorganic fullerene particles as additives can significantly improve the tribological properties of fluids [19-22]. Rapoport et al. conducted a series of experiments and found that IF-WS 2 particles could effectively improve the tribological properties of a material as solid or lubricant [23-25]. Fullerene-like structures can be more effective in reducing friction than corresponding layered structures. Pottuz et al. [26] have studied four possible effects of IF-WS 2 particles in lubricating oil and reasonably explained the anti-friction and anti-wear properties of IF-WS 2 particles. There is a lot of research as lubricating oil additives, including experiments under boundary conditions. They put forward a variety of mechanisms of $\mathrm{WS}_{2}$ particles in lubricating oil, such as delamination of inorganic fullerene nanoparticles, super lubricity of the sheets, a rolling/sliding of the particles, filling micro-pits on worn surfaces with $\mathrm{WS}_{2}$ flakes and forming friction films with iron oxides and sulfides [17,26-31]. At present, the mechanism of IF-WS 2 is still controversial, and their properties still need to be investigated. On this basis, we further studied the potential film composition of friction film under boundary conditions.

The purpose of this work is to analyze the tribological behavior under 75 and $100{ }^{\circ} \mathrm{C}$, attempt to gain an understanding of the specific lubrication mechanism under this condition, and identify the optimal content of IF-WS 2 particles for PAO6 oil, which is widely used in the industry. Moreover, the dispersion and stability of IF-WS 2 in PAO6 were analyzed by means of transmittance and Scanning electron microscopy (SEM). At the same time, the influence of additives in PAO6 on oil temperature was studied with means of variable temperature simulation test and the change of dynamic viscosity of the lubricating oil before and after friction is studied systematically.

\section{Experimental Section}

2.1. Synthesis of IF-WS 2 Particles

IF-WS 2 particles were synthesized by using the Rotary Chemical Vapor Deposition (RCVD) method, according to works of $\mathrm{Xu}$ et al. reported previously [32]. Briefly, $\mathrm{WO}_{3}$ powder was used as the precursor, which reacted under $\mathrm{H}_{2} \mathrm{~S} / \mathrm{Ar}$ atmosphere at $800{ }^{\circ} \mathrm{C}$ for $9 \mathrm{~h}$ in a rotary furnace. Before further use, the samples were ultrasonically cleaned with carbon disulfide solution, filtered and dried in an oven at $80{ }^{\circ} \mathrm{C}$.

\subsection{Preparation of Lubricating Oil}

The base oil used in this study is a low viscosity $\left(5.818 \mathrm{~mm}^{2} / \mathrm{s}\right.$ for kinematic viscosity at $100{ }^{\circ} \mathrm{C}$ ) poly alpha olefin (PAO6, Yuchai Research Institute China), which is the common base oil for various industrial synthetic lubricants. The IF-WS 2 particles were dispersed to the synthetic PAO6 with different mass percentages of $0,0.1,0.25$ and $0.5 \mathrm{wt} \%$ (IF$\mathrm{WS}_{2}$ /PAO6). In total, $3 \mathrm{wt} \%$ Span 80 was used as a surfactant to improve the dispersion stability of additives in oil samples. The IF-WS $2 /$ PAO6 solution was mixed using the ultrasonic treatment for $20 \mathrm{~min}$, and then mechanical stirring for another $10 \mathrm{~min}$ to obtain uniformly mixed lubricants. 


\subsection{Tribological Performance Test}

The tribological behaviors of pure PAO6 and all IF-WS 2 /PAO6 samples were studies at two different temperatures of $75^{\circ} \mathrm{C}$ and $100^{\circ} \mathrm{C}$ by using an MR-10(D) (Jinan Age Testing Machine Co., Ltd., Jinan, China) four-ball friction tester (Schematic diagrams as shown in Figure 1A). The tests were conducted under the conditions of a rotary speed of $1200 \mathrm{rpm}$, under a load of $392 \mathrm{~N}$ and for the duration of $45 \mathrm{~min}$. Before each test, the test balls were washed with petroleum ether to remove organic pollutants on the surface. The friction coefficient was monitored continuously as a function of the number of cycles during the constant temperature test. After the test, the wear scar diameter (WSD) was measured with an optical microscope (Jinan Age Testing Machine Co., Ltd., Jinan, China) equipped with a digital camera. The measurements were repeated 3 times, and the average wear scar diameter (AWSD) value was calculated to ensure the accuracy of the results. Finally, the steel balls, after testing, were cleaned with petroleum ether, dried, marked the wear scar and kept in the sealed sample bags for further SEM and XPS analyses.

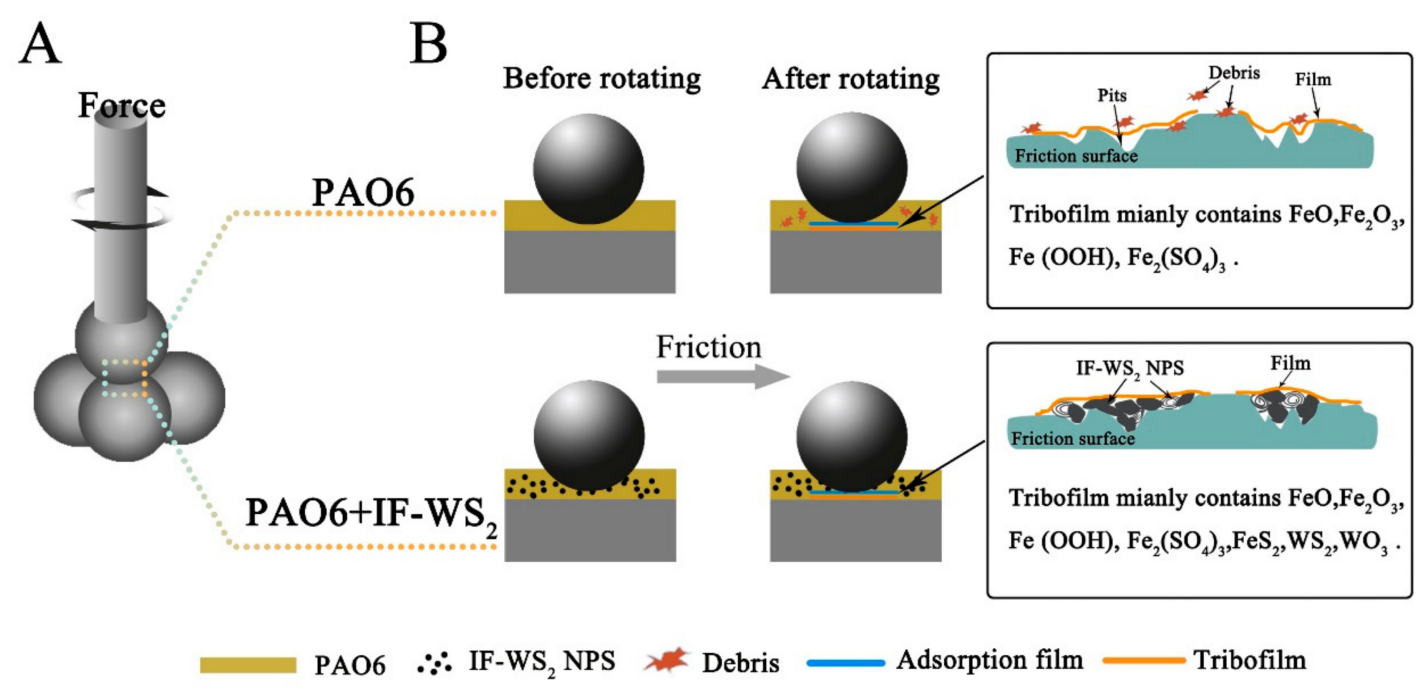

Figure 1. A schematic of (A) the four-ball friction tester used in this study, and (B) the possible lubrication mechanism of $\mathrm{IF}-\mathrm{WS}_{2}$ in the PAO6 oil.

The change of oil temperature in the working process was tested using a $280 \mathrm{~W}$ needle standard lubricating oil anti-wear testing machine. The friction units are composed of a long rod, a short rod, a weight, a grinding ring rotating with the main shaft and a fixed grinding column. That is, a simplified Timken testing machine, the material used in friction pair is stainless steel. The purpose is to test the friction motion between actual mechanical contact surfaces. The test was carried out under a load of $980 \mathrm{~N}$ for $5 \mathrm{~min}$. The data were collected every $20 \mathrm{~s}$, and the average value was obtained after 3 repetitions.

\subsection{Characterization}

The crystal structure and phase composition of IF-WS 2 particles were determined by X-ray diffraction (XRD, Rigaku D/MAX $2500 \mathrm{~V}$, Tokyo, Japan). The morphology of IF-WS 2 particles was studied using a Field-Emission Scanning Electron Microscope (FETEM, FEI TECNAI G2 F30, Washington, DC, USA). After the friction and wear tests, the worn surfaces of the steel ball were characterized using a Scanning Electron Microscope (SEM, Tecnai G2 F30, Washington, DC, USA) and energy-dispersive X-ray spectroscopy (EDS) and laser confocal scanning microscopy (KEYENCE VK-X1000, Osaka, Japan), X-ray photoelectron spectroscopy (XPS, Thermo SCIENTIFIC ESCALAB 250Xi, New York, NY, USA) to study the morphologies, elements and their valence changes of the worn surface. The viscosities of the oil samples before and after the test were measured by a viscometer (CP-3000, Lamyett, Guangzhou, China). 


\section{Results and Discussions}

\subsection{Characterization of IF-WS 2 Particles}

As shown in Figure 2a,b, the IF-WS ${ }_{2}$ particles formed in irregular polygonal shapes with an average size of around $100-200 \mathrm{~nm}$. The surface agglomeration of IF-WS 2 spheroids is also observed and probably caused by the fusion of adjacent $\mathrm{WO}_{3}$ during the heating process. The TEM image (Figure $2 \mathrm{c}-\mathrm{e}$ ) show that IF- $\mathrm{WS}_{2}$ presented the typical hollow core structures consisting of a large number of layers. The thickness of each layer is $0.62 \mathrm{~nm}$, which matches well with the standard d-space value of the (002) plane of $\mathrm{WS}_{2}$. Our morphologies results agree well with Tenne et al. works [33]. Moreover, the TEM results also suggest that the agglomeration of these nanoparticles occurred before the conversion of oxide to sulfide [32].
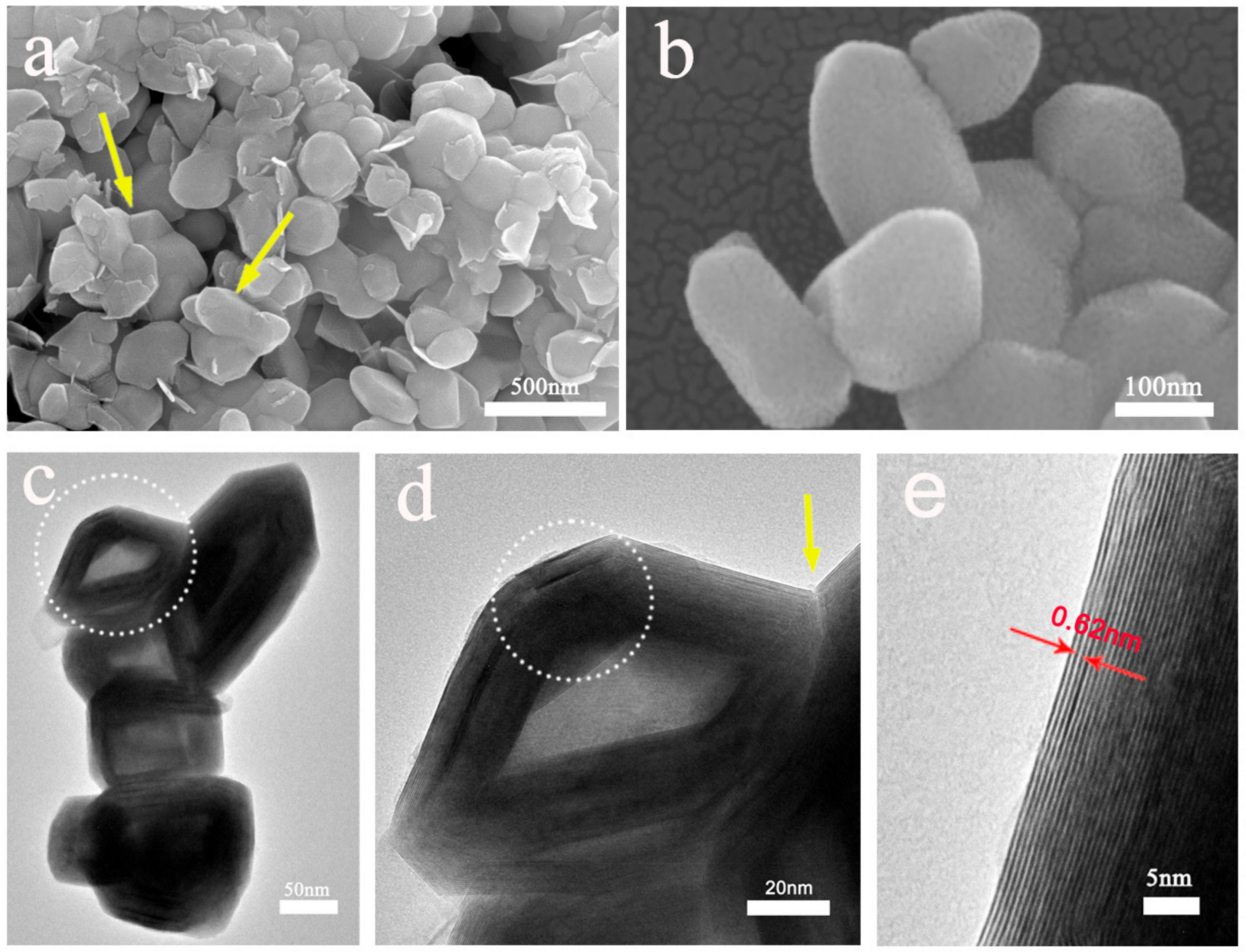

Figure 2. (a,b) The Scanning Electron Microscope (SEM) and (c-e) Transmission Electron Microscopy (TEM) images of IF-WS 2 particles.

Figure 3a shows the XRD diffraction patterns of the synthesized product. The observed diffraction peaks in the XRD pattern are characteristic peaks of the $\mathrm{WS}_{2}$, which is in accordance with the JCPDS card No. $84-1398$ data. The sharp $\mathrm{WS}_{2}$ peak is at $2 \theta=14.2^{\circ}$ corresponding to the (002) crystalline planes, of which the layers occur at 90 degrees to the radial direction of the particles. The peaks at $23-25^{\circ}$ are attributed to the $\mathrm{WO}_{\mathrm{x}}$ residue in the core of some IFs. The (002) peak shifts to the left, and both (103) and (105) peaks also broaden in the IF-WS ${ }_{2}$ XRD profile [34]. All the peak locations in the XRD patterns are also consistent with those reported in the literature [32]. Compared with the characteristic peak position of the XRD spectrum of $\mathrm{WO}_{3}$ (the place marked by an asterisk), there is nearly $\mathrm{WO}_{3}$ residue in the product, and the composition of the product is further determined by 
XPS. The presence of $\mathrm{W}$ and S elements is confirmed by XPS analysis and presented as high-resolution XPS spectra of $W 4 f$ and $S 2 p$ (Figure $3 b$ ). Two $S 2 p$ peaks of $S 2 p_{3 / 2}$ and $S$ $2 \mathrm{p}_{1 / 2}$ at 162.2 and $163.2 \mathrm{eV}$ respectively, are corresponded to $\mathrm{S}^{2-}$ in $\mathrm{WS}_{2}[35,36]$. For the $\mathrm{W}$ 4f spectrum, the peaks locate at $32.4,34.5$ and $38.0 \mathrm{eV}$ can be assigned to $\mathrm{W}^{4+} 4 \mathrm{f}_{7 / 2}, \mathrm{~W}^{4+}$ $4 \mathrm{f}_{5 / 2}$ and $\mathrm{W}^{6+} 4 \mathrm{f}_{5 / 2}$, respectively $[35,36]$. The existence of $\mathrm{W}^{6+}$ may be attributed to $\mathrm{WO}_{\mathrm{x}}$ residues in some IFs cores, or the light surface oxidation of particles cannot be ruled out. Based on the XRD, TEM and XPS results, we can confirm that the quality of the IF-WS ${ }_{2}$ comparable with those reported.
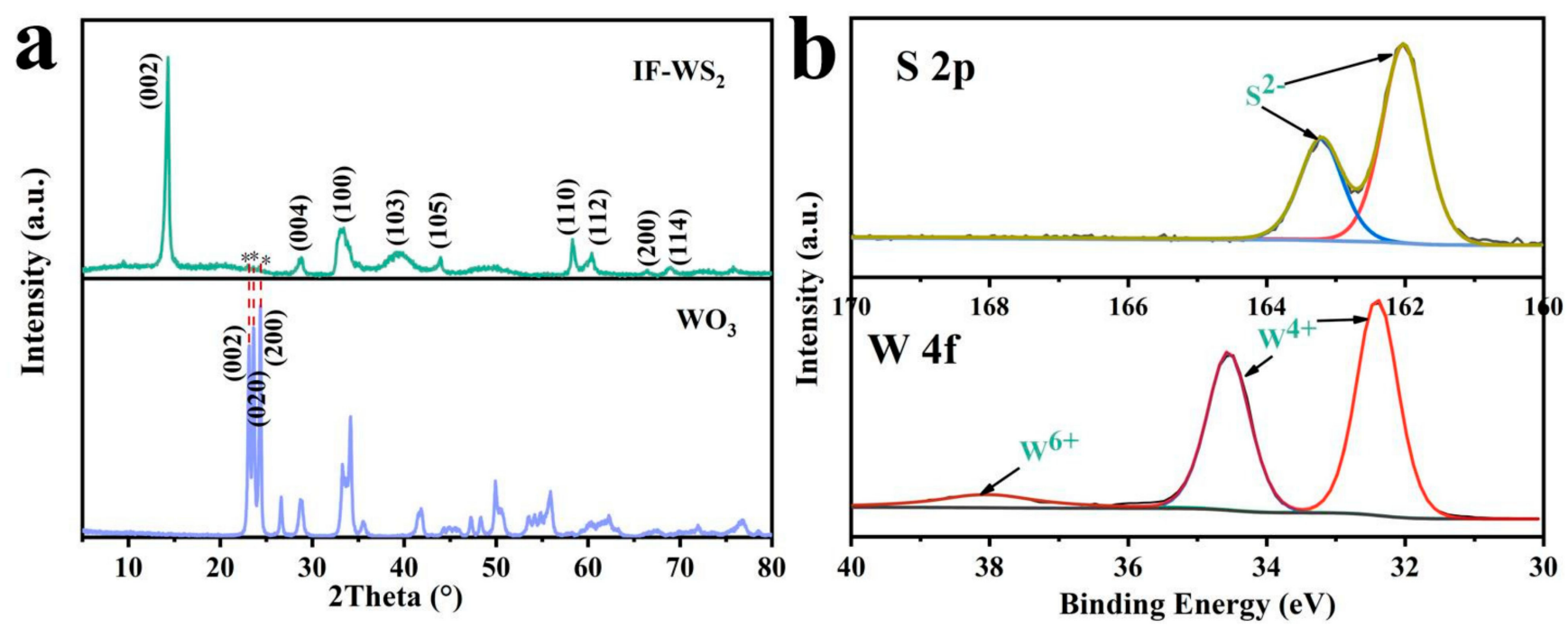

Figure 3. (a) The X-ray Diffraction (XRD) patterns of IF-WS 2 NPs; (b) X-ray photoelectron spectroscopy (XPS) spectra of S $2 \mathrm{p}, \mathrm{W} 4 \mathrm{f}$

\subsection{Analysis of Friction and Wear Test}

The coefficient of friction (COF) curve, the average coefficient of friction (AF) and the average wear scar diameter (AWSD) of the tested steel ball is presented in Figures 4 and 5. The friction coefficient curve presents a high friction noise at the beginning of the test (time area between 0-250 s) due to the friction has entered the running-in stage. Thus, the iron scraps generated during the friction process are mixed into the PAO6 oil resulting in abrasive wear and increasing the coefficient of friction. The friction coefficient tends to be more stable at the end of the running-in stage due to the formation of a physical or chemical protective film on the surface (Table 1) [37,38]. After the running-in stage, the curve of IF-WS 2 /PAO6 lubricant tends to decrease gradually over time. It is suggested that a little IF-WS $\mathrm{W}_{2}$ particles gathered on the surface of the friction pair during the friction test. Under high pressure, the outer shell of the IF- $\mathrm{WS}_{2}$ with cage structure could be peeled off during the period of the running-in stage, which changed the wear couple from point contact to surface contact to lubricate and reduce the coefficient of friction, just as the research of Maharaj and Joly-Pottuz et al. [39-42]. In addition, we noticed that the friction coefficient curve of the oil sample without span 80 dispersant is higher in Figure 4b. It may be due to the poor dispersion of IF-WS ${ }_{2}$ in PAO6 oil, and the larger aggregates are not easy to enter the contact area, which leads to the larger friction coefficient and poor lubrication performance.

A diagram of AF of pure PAO6 and IF-WS 2 /PAO6 samples at $75^{\circ} \mathrm{C}$ shows that the pristine PAO6 without IF- $\mathrm{WS}_{2}$ addition exhibits the highest AF of 0.124 . The AF of PAO6 with $0.1 \%$ and $0.25 \%$ IF-WS 2 decreases to 0.110 and 0.105 , respectively. The COF carves of $0.25 \mathrm{wt} \% \mathrm{IF}-\mathrm{WS}_{2}$ are relatively stable with time. A similar trend is also observed for the $0.1 \mathrm{wt} \%$ of IF-WS 2 samples during the first $1750 \mathrm{~s}$, followed by a continuous increase until the end of the record. We suggest that this behavior might be justified by the aggregation and sedimentation phenomena of the IF-WS 2 particles, which made it hard for them to get 
access evenly to the contact areas and therefore limited their presence between the moving surface. When the content of IF-WS 2 particles increased to $0.5 \mathrm{wt} \%$, compared with the pure oil PAO6, its friction curve fluctuates greatly, with an AF value of 0.121. Based on this experiment, we confirm that the anti-friction effect of base oil can be enhanced with the addition of the IF-WS ${ }_{2}$ additives. The AF is reduced by $11.3,15.3$ and $2.4 \%$ for $0.1,0.25$ and $0.5 \mathrm{wt} \% \mathrm{IF}-\mathrm{WS}_{2}$ additive content, respectively, benchmarked against the pure PAO6.

At $100{ }^{\circ} \mathrm{C}$, the AF of pure PAO6 oil increases to 0.135 , which was higher than the test result at $75^{\circ} \mathrm{C}$. When $0.1,0.25$ and $0.5 \mathrm{wt} \%$ of IF- $\mathrm{WS}_{2}$ particles were added, the AF reduces to $0.0978,0.0979$ and 0.0974 , respectively. Its anti-friction performance slightly improves with the increase of IF-WS 2 additive content, by about $27 \%$ compared with that of pure PAO6. In short, the IF-WS 2 additives exhibited a better anti-friction effect than pure PAO6, particularly at higher temperatures.
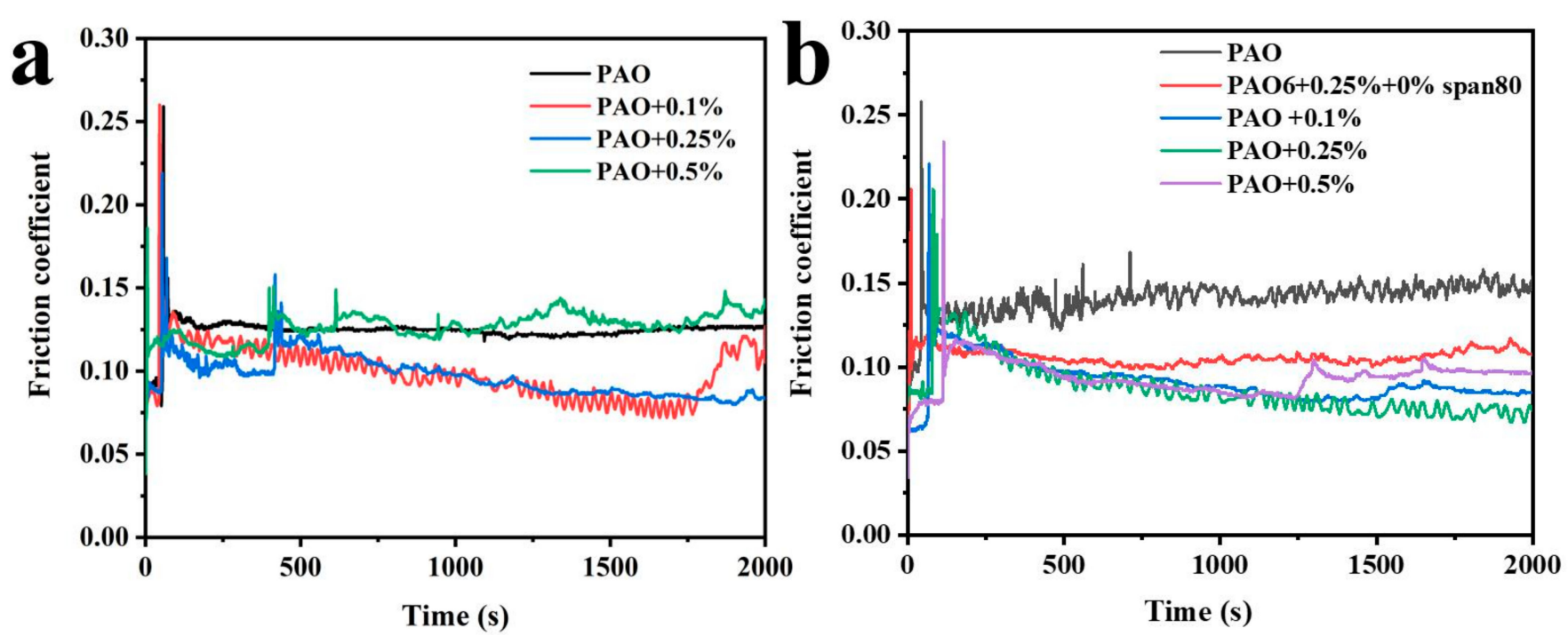

Figure 4. The coefficient of friction (COF) curve of IF-WS 2 with different contents at temperatures (a) $75^{\circ} \mathrm{C}$ and (b) $100{ }^{\circ} \mathrm{C}$ with the load of $392 \mathrm{~N}$ and rotation speed of $1200 \mathrm{rpm}$.
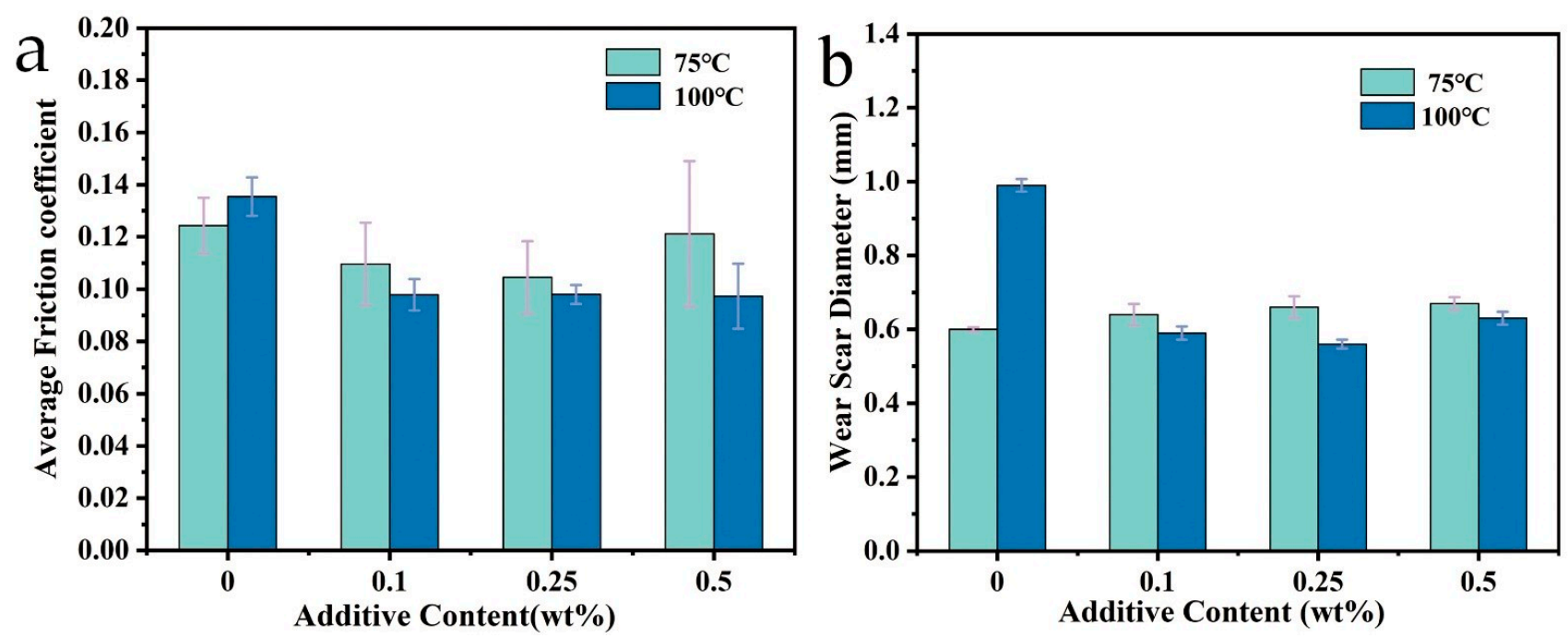

Figure 5. (a) average coefficient of friction (AF) and (b) average wear scar diameter (AWSD) diagram of different IF-WS 2 contents at $75^{\circ} \mathrm{C}$ and $100{ }^{\circ} \mathrm{C}$. 
Table 1. Average COF values at different time.

\begin{tabular}{|c|c|c|c|c|c|}
\hline \multirow{2}{*}{ Temperature $\left({ }^{\circ} \mathrm{C}\right)$} & \multirow{2}{*}{ Content of IF-WS $(w t \%)$} & \multicolumn{4}{|c|}{ Average Coefficient of Friction (COF) } \\
\hline & & $500 \mathrm{~s}$ & $1000 \mathrm{~s}$ & $1500 \mathrm{~s}$ & $2000 \mathrm{~s}$ \\
\hline \multirow{4}{*}{75} & 0 & 0.124 & 0.124 & 0.122 & 0.127 \\
\hline & 0.1 & 0.104 & 0.096 & 0.085 & 0.127 \\
\hline & 0.25 & 0.121 & 0.097 & 0.086 & 0.083 \\
\hline & 0.5 & 0.124 & 0.129 & 0.088 & 0.142 \\
\hline \multirow{4}{*}{100} & 0 & 0.130 & 0.147 & 0.144 & 0.146 \\
\hline & 0.1 & 0.097 & 0.0880 & 0.081 & 0.086 \\
\hline & 0.25 & 0.096 & 0.086 & 0.072 & 0.067 \\
\hline & 0.5 & 0.094 & 0.086 & 0.096 & 0.096 \\
\hline
\end{tabular}

The AWSD of PAO6 containing IF-WS 2 particles at $75{ }^{\circ} \mathrm{C}$ is slightly larger than that of pure PAO6, which increases by $6.7 \%, 10 \%$ and $11.7 \%$, respectively, and it weakens the anti-wear performance of base oil, as shown in Figure $5 \mathrm{~b}$. At $100{ }^{\circ} \mathrm{C}$, the AWSD obtained for lubricants based on PAO6 containing 0.1, 0.25 and $0.5 \mathrm{wt} \%$ of IF-WS ${ }_{2}$ additives are $0.59,0.56$ and $0.63 \mathrm{~mm}$, respectively. Compared with $0.99 \mathrm{~mm}$ of the pristine PAO6, which converts to a decrease of AWSD by $40.4 \%, 43.4 \%$ and $35.4 \%$. The reason for the above situation may be that the test temperature affects the lubrication performance of additive IF-WS 2 particles. At high temperatures, the degree of freedom of particles in base oil PAO6 is relatively large. Once the protective film is destroyed, they can form boundary films on the contact surface faster. However, the viscosity of the base oil is relatively high at low temperatures, which limits the movement of particles. The particles at the contact interface cannot be replenished in time, resulting in serious wear and tear [43].

As shown in the point plot of Figure 5, some data of AF and AWSD show a valley trend with the change of IF-WS $\mathrm{WS}_{2}$ concentration, and there is a common valley point between them, which corresponds to the optimal content of IF-WS ${ }_{2}$. In addition, the anti-friction and anti-wear performance of pure PAO6 oil is poor. It may be the dispersion of high concentration IF- $-\mathrm{WS}_{2}$ in lubricating oil decreases. IF-WS 2 additive has a large amount of agglomeration and deposition, which results in poor wear [44-46]. The error bar in the figure shows that the repeatability of the experiment is high, and the error is less than $3 \%$.

The effect of $\mathrm{WS}_{2}$ on the wear performance of POA6 was analyzed and with 3D topography (Figure 6) and wear profile (Figure 7). At $75^{\circ} \mathrm{C}$, there are many wear scratches on the worn surfaces of oil POA6 (Figure 6a) and $0.25 \mathrm{wt} \% \mathrm{IF}-\mathrm{WS}_{2} / \mathrm{PAO}$ (Figure $6 \mathrm{~b}$ ). Additionally, the scratches of $0.25 \mathrm{wt} \% \mathrm{IF}-\mathrm{WS}_{2} / \mathrm{PAO} 6$ are deep and even dense, deep furrows appear, and the right side of the worn surface is more obvious, as shown in Figure 7a. Its surface roughness is larger, and the wear is more serious. Compared with PAO6, wear surface area increases from $10,581.03 \mu \mathrm{m}^{2}$ to $24,402.96 \mu \mathrm{m}^{2}$ (Table 2). The furrows of $0.25 \mathrm{wt} \% \mathrm{IF}-\mathrm{WS}_{2} / \mathrm{PAO} 6$ contain more wear debris, which may be caused by viscosity at low temperatures. It prevents the wear debris and IF-WS $\mathrm{W}_{2}$ in scratches from flowing out with lubricating oil in time and accumulating into large particles, which causes abrasive wear and ploughed the worn surfaces leads to more furrows.

Table 2. The average wear area data of IF- $\mathrm{WS}_{2} / \mathrm{PAO} 6$ lubricants with different contents at different temperatures.

\begin{tabular}{ccccc}
\hline & \multicolumn{2}{c}{$75^{\circ} \mathrm{C}$} & \multicolumn{2}{c}{$100{ }^{\circ} \mathrm{C}$} \\
\hline & PAO6 & PAO6 + 0.25\% & PAO6 & PAO6 + 0.25\% \\
\hline Average area $\left(\mu \mathrm{m}^{2}\right)$ & 10581.03 & 24402.96 & 28801.48 & 12062.06 \\
\hline
\end{tabular}



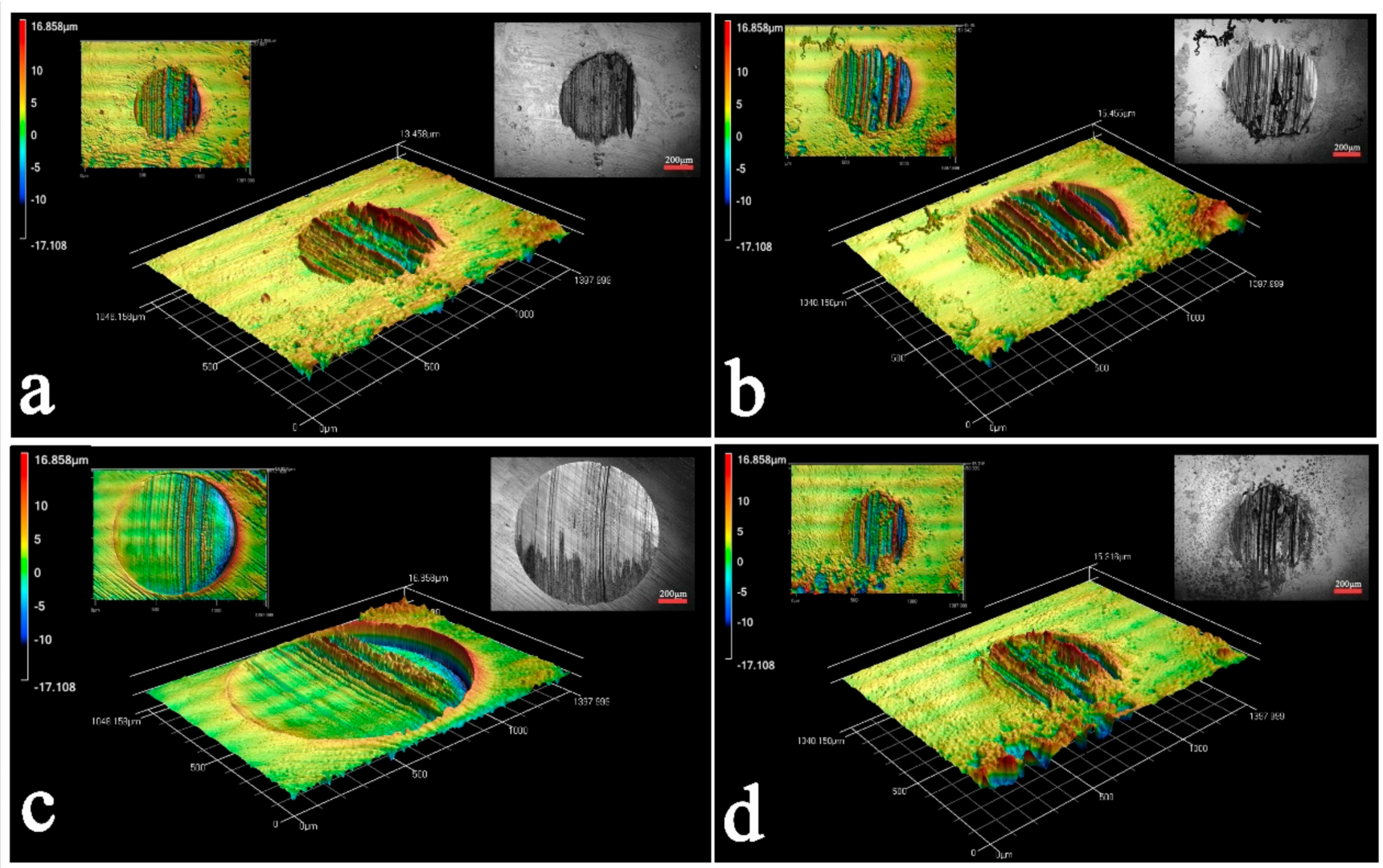

Figure 6. 2D and 3D morphologies of wear surfaces of pure PAO6 and $0.25 \mathrm{wt} \% \mathrm{IF}-\mathrm{WS}_{2} / \mathrm{PAO} 6$ at $75^{\circ} \mathrm{C}(\mathbf{a}, \mathbf{b})$ and $100{ }^{\circ} \mathrm{C}(\mathbf{c}, \mathbf{d})$.
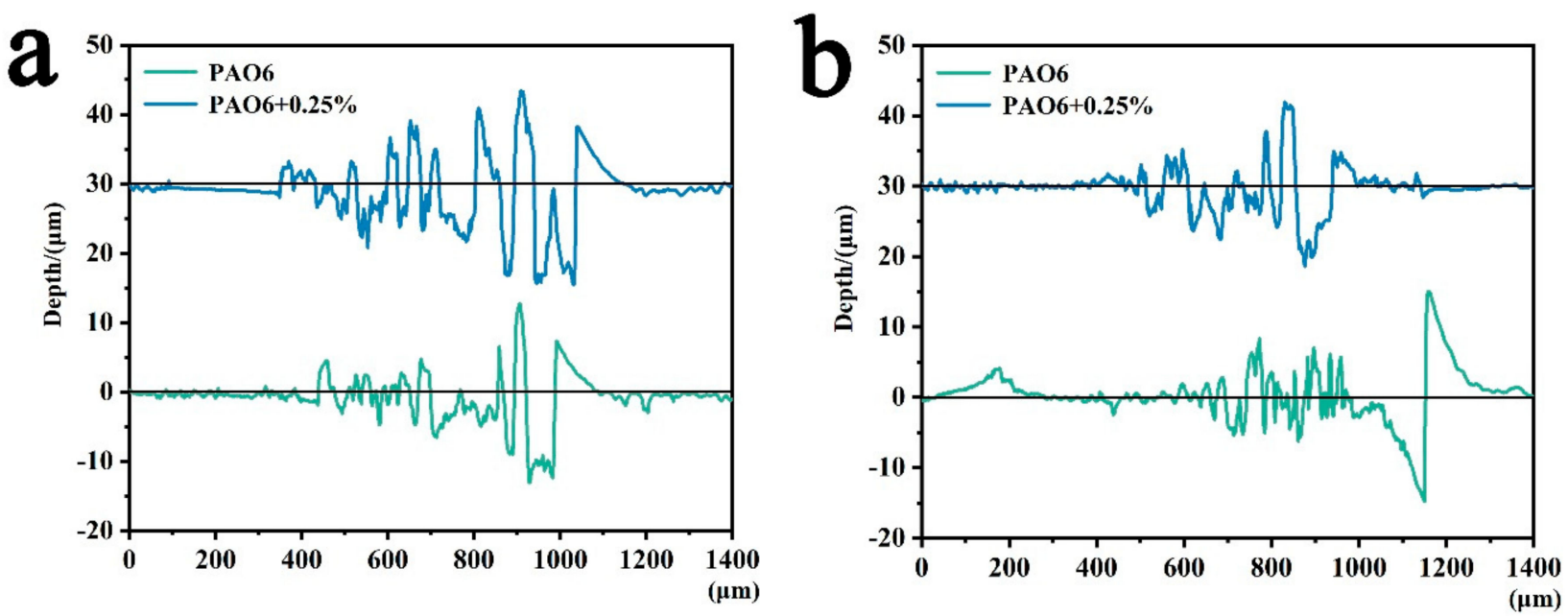

Figure 7. Wear profile curve of pure PAO6 and $0.25 \mathrm{wt} \% \mathrm{IF}-\mathrm{WS}_{2} / \mathrm{PAO} 6$ at $75{ }^{\circ} \mathrm{C}(\mathbf{a})$ and $100{ }^{\circ} \mathrm{C}(\mathbf{b})$.

To further analyze the lubrication process of the IF-WS 2 additive, the surface morphology of wear scars that occurred with different additive concentrations were observed, as shown in Figure 8. The SEM images show that the wear scar of the pristine PAO6 oil looked very rough, there are large areas of damage and debris (Figure $8 a_{2}, a_{3}$ ), and the worn surface exhibit many large pits and deep furrows at $100{ }^{\circ} \mathrm{C}$ (Figure $8 c_{2}, c_{3}$ ). Compared with the $75^{\circ} \mathrm{C}$ samples, the damage at $100{ }^{\circ} \mathrm{C}$ is more serious, and the overall anti-wear performance is poor. In contrast, the wear scar for samples of PAO6/IF-WS became $^{2}$ smoother. The roughness and debris of the wear scar surface are significantly reduced, although the width of the wear scar is not reduced at $75^{\circ} \mathrm{C}$. This may be attributed to the 
agglomeration and the chemical-curing phenomenon of nanoparticles with a high concentration. Therefore, it is hard for $\mathrm{WS}_{2}$ to form a continuous and uniform anti-friction layer on the friction region [47]. The defects become shallower, which made the wear slightly reduced, as shown in Figure $8 b_{2}, b_{3}$. The wear scar width and the plough grooves became much smaller at $100{ }^{\circ} \mathrm{C}$. The pits basically disappear without obvious defects, the friction surface became very smooth, which indicates a better wear resistance (Figure $8 d_{2}, d_{3}$ ).
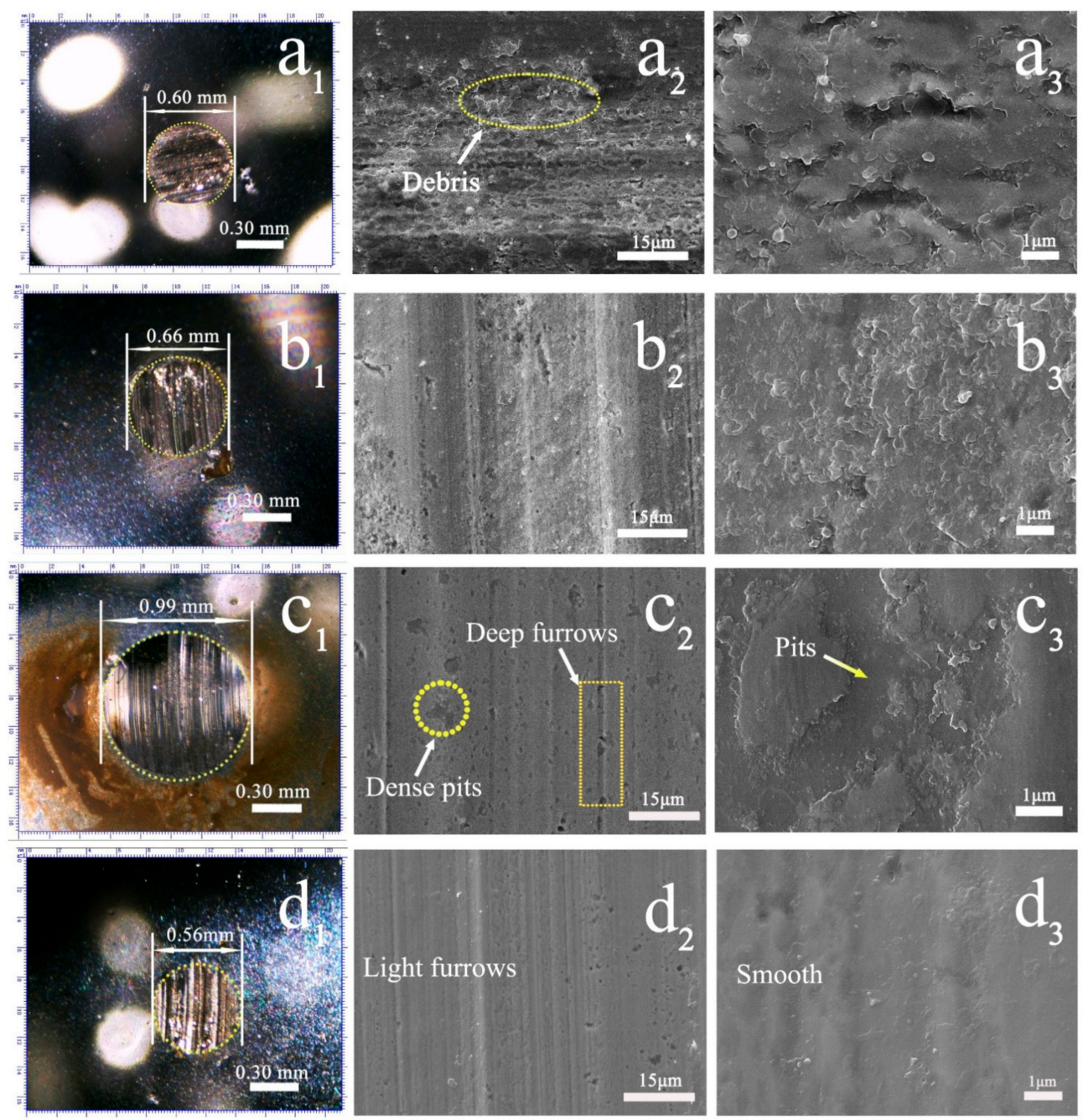

Figure 8. WSD photos and SEM images of the worn samples after tests. (a) pristine PAO6 oil at $75^{\circ} \mathrm{C}$, (b) $0.25 \mathrm{wt} \%$ IF-WS 2 particles at $75^{\circ} \mathrm{C}$, and (c) pristine PAO6 oil at $100{ }^{\circ} \mathrm{C}$, (d) $0.25 \mathrm{wt} \% \mathrm{IF}-\mathrm{WS}_{2}$ particles at $100^{\circ} \mathrm{C}$.

The results of each EDS diagram show that $\mathrm{W}$ and $\mathrm{S}$ elements are distributed on the worn surface of PAO6 lubricating oil containing IF-WS ${ }_{2}$ (Figure 9), which confirmed that these particles are indeed located at the contact interface and are involved in the friction process. They directly fill the grooves or peeled off sheets of the out layers from the $\mathrm{WS}_{2}$ to fill the pits, thus repairs damages to the surface. This sort of tribo-film can improve the wear resistance, as illustrated by Tenne et al. [48]. These analyses are consistent with the test data, also prove that the addition of additive IF-WS 2 particles can obviously improve anti-wear performance of PAO6 oil. The higher the temperature is, the more obvious effect will improve. 

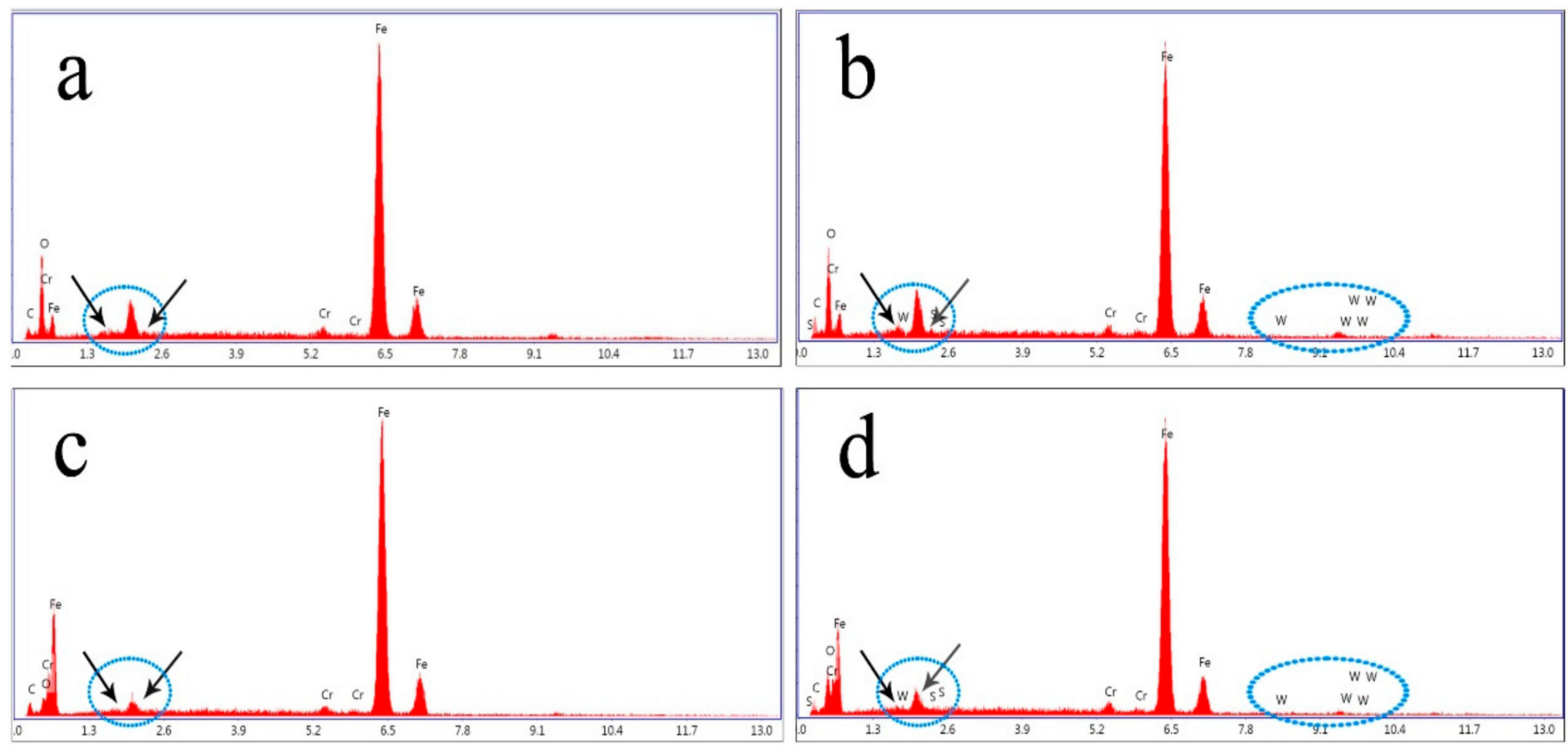

Figure 9. EDS profiles of the surface after friction process samples, under (a) pristine PAO6 oil and (b) PAO6 containing $0.25 \mathrm{wt} \% \mathrm{IF}-\mathrm{WS}_{2}$ at $100{ }^{\circ} \mathrm{C}$; and (c) pristine PAO6 oil and (d) PAO6 containing $0.25 \mathrm{wt} \% \mathrm{IF}-\mathrm{WS}$, particles at $75^{\circ} \mathrm{C}$.

XPS is used to analyze the change of chemical state of elements in the PAO6 oil during friction, which is very helpful for understanding the lubrication mechanism of the additives. As shown in Figure 10, despite the high temperature, the XPS spectra of typical elements $C 1 s, S 2 p, W$ f and Fe $2 p$ are observable on the worn surface, which is obtained after correlating with the $\mathrm{C} 1 \mathrm{~s}$ binding energy of $284.8 \mathrm{eV}$. There are three peaks of $\mathrm{C}-\mathrm{C} / \mathrm{C}-\mathrm{H}(284.8 \mathrm{eV}), \mathrm{C}=\mathrm{C}(286.6 \mathrm{eV})$ and $\mathrm{C}=\mathrm{O}(288.6 \mathrm{eV})$ in the $\mathrm{C} 1 \mathrm{~s}$ spectrum [46,49], which shows that the addition of additives has no influence on the structure of organic content in the PAO6 oil. At $75{ }^{\circ} \mathrm{C}$, the XPS spectra of S $2 \mathrm{p}$ had almost no difference, and the peak at a binding energy of $168.6 \mathrm{eV}$ corresponded to the $\mathrm{S}^{4+}$ state and occurred in $\mathrm{FeSO}_{4}$ or $\mathrm{Fe}_{2}\left(\mathrm{SO}_{4}\right)_{3}$ [43] (Figure 10a,b). The XPS spectrum of W $4 \mathrm{f}$ consists of 3 peaks, corresponding to $\mathrm{WS}_{2}(33.2 \mathrm{eV})$ and $\mathrm{WO}_{3}(35.4$ and $37.8 \mathrm{eV})$, respectively, indicating that the wear trace contains IF-WS 2 NPs or peeling pieces [43,50]. For the Fe $2 p$ spectrum, there are $\mathrm{Fe}_{2}\left(\mathrm{SO}_{4}\right)_{3}, \mathrm{Fe}(\mathrm{OOH}), \mathrm{Fe}_{2} \mathrm{O}_{3}$ or $\mathrm{Fe}_{3} \mathrm{O}_{4}$ signals, at binding energies of $724.8,711.5$ and $710.4 \mathrm{eV}$, respectively $[43,46]$. In particular, the $\mathrm{FeO}(709.3 \mathrm{eV})$ peak appears on the worn surface in the pristine PAO6 oil sample, whilst in the IF-WS 2 /PAO6 sample, a similar peak exists at $706.9 \mathrm{eV}$, which matches with $\mathrm{FeS}_{2}$ [43]. The new peak of $\mathrm{Fe}_{2} \mathrm{~S}$ seems to have confirmed that a chemical reaction between the exfoliated pieces of IF- $\mathrm{WS}_{2}$ particles and the steel ball matrix occurred. When the test temperature is constant at $100{ }^{\circ} \mathrm{C}$, the $\mathrm{S} 2 \mathrm{p}$ spectrum exhibits sulfide (near $162.5 \mathrm{eV}$ ) and sulfur oxide/sulfate $(168.9 \mathrm{eV})$ signals, while the sulfide signal value with additives is weak $[43,50]$. The $W$ ff spectrum shows the signals of the two substances the same as that observed at $75^{\circ} \mathrm{C}$. The $\mathrm{FeS}_{2}$ peak also appears at the binding energy of $706.7 \mathrm{eV}$ of $\mathrm{Fe} 2 \mathrm{p}$ for the $100{ }^{\circ} \mathrm{C}$ pristine PAO6 samples (Figure 10c), which may be that the test temperature rose and the $\mathrm{Fe}$ compound reacted with the original $\mathrm{S}$ element in the steel ball. However, this is not for samples with $\mathrm{WS}_{2}$ at $100{ }^{\circ} \mathrm{C}$, as shown in Figure 10d. According to the peak analysis of $\mathrm{S} 2 \mathrm{p}$ from $100{ }^{\circ} \mathrm{C} \mathrm{IF}-\mathrm{WS}_{2} / \mathrm{PAO} 6$ sample, the $\mathrm{FeS}_{2}$ peak should have appeared in $\mathrm{Fe} 2 \mathrm{p}$, which possibly because the worn surface is covered by most $\mathrm{WS}_{2}$ films. It leads to weakened or even the disappearance of the $\mathrm{Fe}_{2} \mathrm{~S}$ signal. This consists well with the results of our SEM analysis. 
$\mathbf{a}$
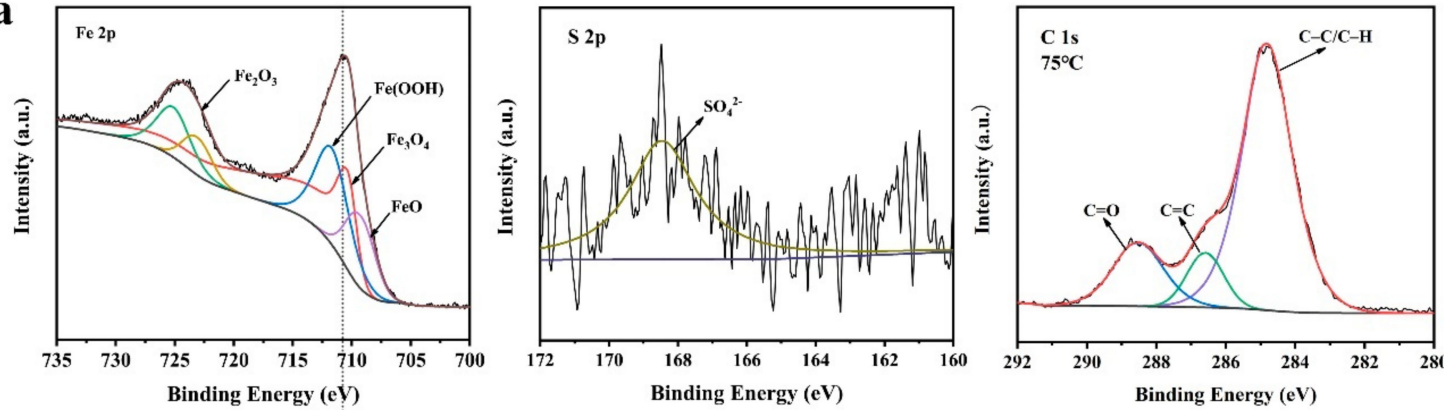

b
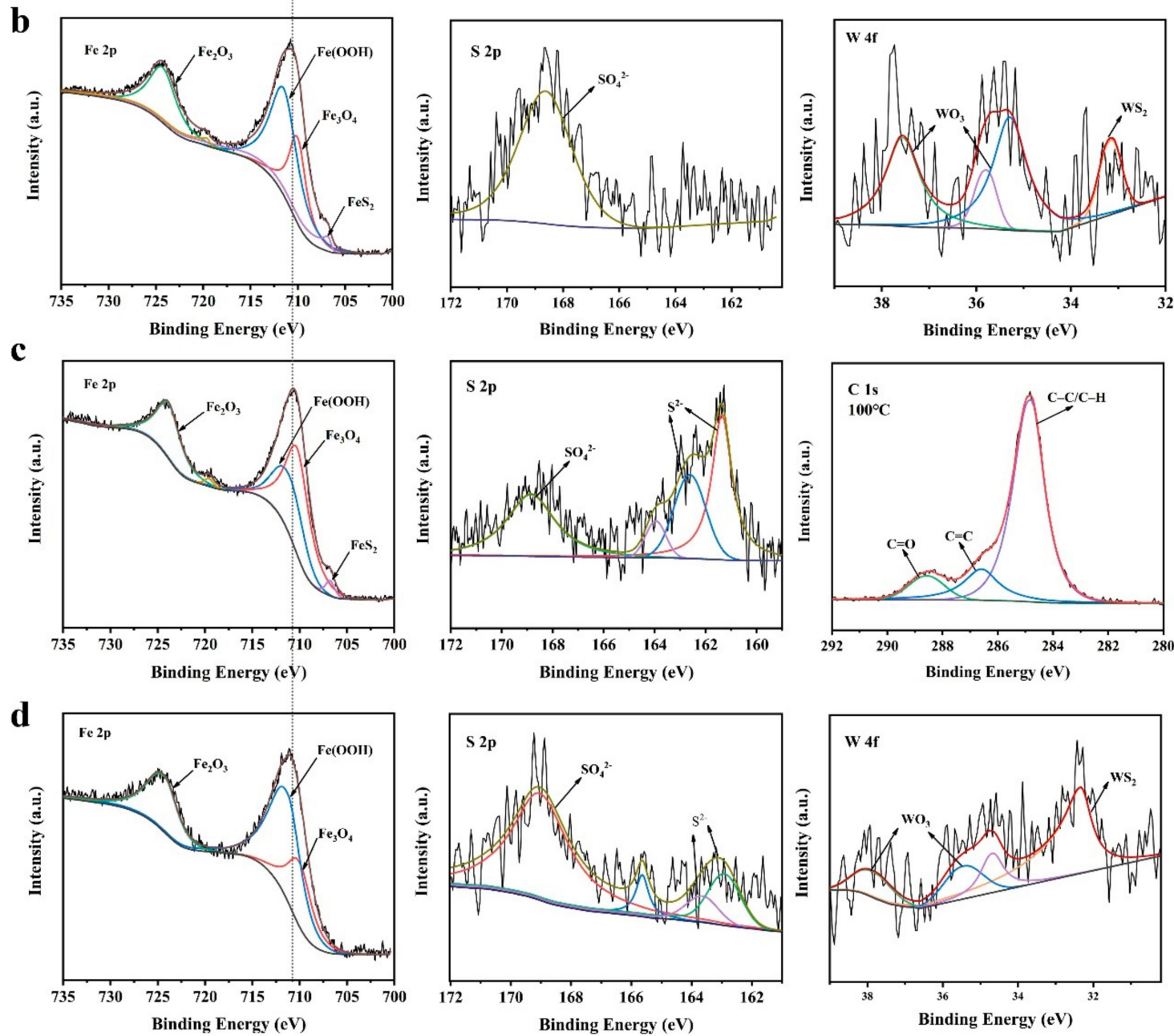

Figure 10. XPS spectra of the elements (C 1s, Fe 2p, S 2p and W 4f) on the worn surfaces, lubricated by pristine PAO6 at (a) $75^{\circ} \mathrm{C}$, (b) $75^{\circ} \mathrm{C}$ and (c) $100{ }^{\circ} \mathrm{C}$, and by PAO6 containing $0.25 \mathrm{wt} \% \mathrm{WS}_{2}$ at (d) $100{ }^{\circ} \mathrm{C}$.

A schematic of the lubrication mechanism is proposed, as shown in Figure 1B. Chemical reaction occurred on the contact surface during friction, and tribo-films formed. For the pristine PAO6 oil, iron filings are oxidized to form boundary protective films of $\mathrm{Fe}_{2} \mathrm{O}_{3}$, $\mathrm{Fe}_{3} \mathrm{O}_{4}, \mathrm{Fe}(\mathrm{OOH})$ and $\mathrm{Fe}_{2}(\mathrm{SO} 4)_{3}$. In the case of using IF- $\mathrm{WS}_{2}$ additives, the formed boundary protective films consist of $\mathrm{FeS}_{2}, \mathrm{WS}_{2}$ and $\mathrm{WO}_{3}$, apart from $\mathrm{Fe}_{2} \mathrm{O}_{3}, \mathrm{Fe}_{3} \mathrm{O}_{4}, \mathrm{Fe}(\mathrm{OOH})$ and $\mathrm{Fe}_{2}\left(\mathrm{SO}_{4}\right)_{3}$. The protective films were very complex and advanced, were attached to the friction surface of the steel balls, which prevented its direct contact between the wear couple. The IF- $\mathrm{WS}_{2}$ additives could make up for the micro-pits and damages caused by the uneven distribution of iron-related oxides and therefore reduced friction and exhibited improved anti-wear performance. 


\subsection{The Dispersion Stability of IF-WS 2 in PAO6 Oil}

The dispersion stability of particles was detected by the transmittance of an ultraviolet spectrophotometer, and the transmittance of the system was the smallest, which indicated that the system had the best dispersion stability. Figure 11 is a graph of the relationship between different addition contents and transmittance with wavelengths of (a) $400 \mathrm{~nm}$ and (b) $630 \mathrm{~nm}$. It can be seen from Figure 11 that with the passage of time, IF-WS 2 particles with various initial concentrations have a tendency of gradually gathering and sinking in PAO6. (a) and (b) indicate that $0.1 \%$ IF-WS 2 lubricating oil after standing for $24 \mathrm{~h}$ has particle aggregation, which leads to a decrease in the concentration of upper particles, and the curve transmittance at this time is about $5 \%$. It may be because $0.25 \%$ and $0.5 \%$ of IF-WS 2 /PAO6 are saturated, while $0.1 \%$ is not saturated, which is different. The light transmittance is greater than $0.25 \%$ after standing for a period of time. After standing for $72 \mathrm{~h}$, the transmittance of $0.25 \%$ and $0.5 \%$ IF-WS 2 oil samples is different, and the $0.5 \% \mathrm{IF}-\mathrm{WS}_{2}$ oil samples aggregate faster, which may be due to the high concentration of IF-WS 2 particles in lubricating oil, the large interaction force between particles, and the weak stability of micelle formed by span 80 coating, which leads to particle aggregation. The difference between them is more obvious after standing for $120 \mathrm{~h}$. After standing for $192 \mathrm{~h}$, the transmittance of the two is basically the same, which may be because the gravity of $0.25 \% \mathrm{IF}-\mathrm{WS}_{2}$ plays a major role at this time, resulting in obvious particle aggregation and sedimentation.
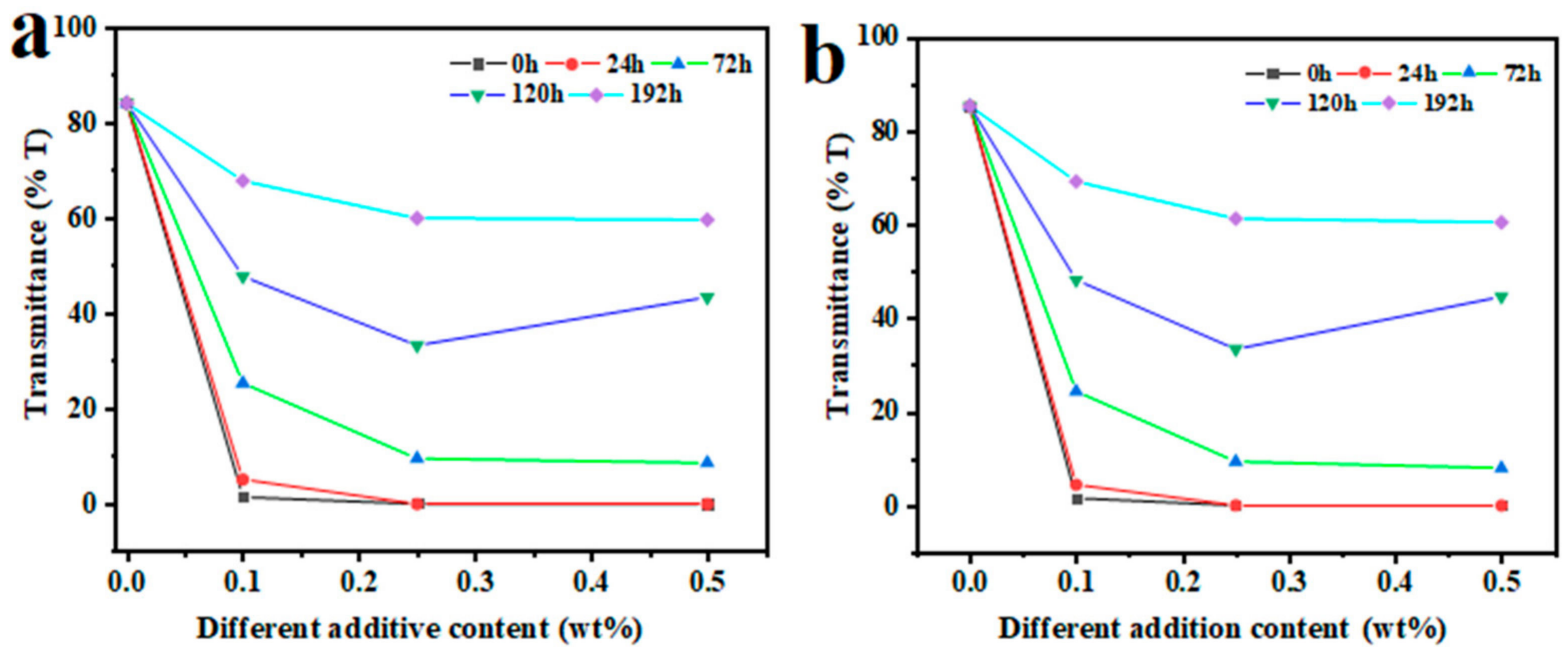

Figure 11. Graph of the relationship between different addition contents and transmittance with wavelengths of (a) $400 \mathrm{~nm}$ and (b) $630 \mathrm{~nm}$.

In order to analyze the reason why IF-WS 2 particles disperse well in PAO6 oil, the dispersion effect of IF-WS ${ }_{2}$ particles was observed by scanning electron microscope. Figure $12 \mathrm{a}$ is an SEM image of $0.25 \% \mathrm{PAO} 6 / \mathrm{IF}-\mathrm{WS}_{2}$ without active agent span 80 . The figure shows that IF-WS 2 particles have an obvious agglomeration phenomenon. Figure $12 \mathrm{~b}$ is an SEM image of $0.25 \%$ PAO6/IF-WS 2 containing active agent span 80 . The figure shows that IF-WS ${ }_{2}$ with span 80 dispersant has good dispersivity and no obvious agglomeration. The reason is that the long-chain alkane at one end of the active agent span 80 has good compatibility with the base oil PAO6, which increases the wettability of IF-WS ${ }_{2}$ in PAO6 and reduces its surface energy. The other end is adsorbed on the surface of IF-WS 2 particles to form a solvated film, as shown by the arrow in Figure 12b. At the same time, the polymer adsorbed by particles will produce new repulsive energy, increase the space distance, weaken the attraction between molecules, and effectively prevent the mutual contact between particles, thus maintaining a stable state and reducing agglomeration [51,52]. Span 80 can effectively improve the dispersion of IF-WS 2 , thereby improving the performance of IF-WS $\mathrm{WS}_{2}$ in POA6 lubrication performance. 

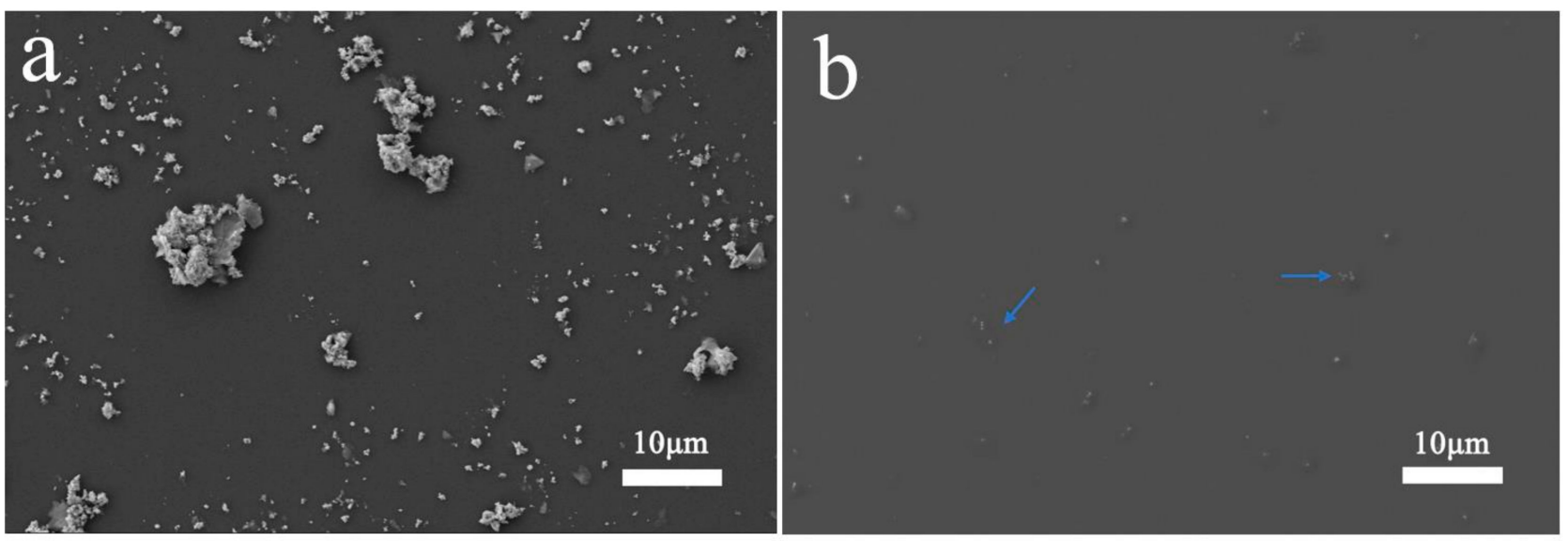

Figure 12. SEM of dispersion of (a) IF-WS 2 /PAO6 without span 80 and (b) IF-WS $/$ PAO6 with span 80 with the content of $0.25 \%$.

\subsection{Physical Properties of the Lubricating Oil}

The actual working condition of the PAO6 oil with IF-WS 2 particles is evaluated by a $280 \mathrm{~W}$ pointer standard lubricating oil anti-wear testing machine. The change of oil temperature during the friction test is shown in Figure 13a. In the working process, the oil temperature of pristine PAO6 oil reaches $89.9^{\circ} \mathrm{C}$ at $200 \mathrm{~s}$ and then tends to stabilize. The temperature of those containing $0.1,0.25$ and $0.5 \mathrm{wt} \% \mathrm{IF}-\mathrm{WS}_{2}$ reached $50.5,48.5$ and $54{ }^{\circ} \mathrm{C}$, respectively, at $300 \mathrm{~s}$, which have a slower rate of oil temperature rise and a lower platform trend. These results showed that the additives effectively delay the rise of oil temperature, of which the $0.25 \mathrm{wt} \%$ content is the most effective. IF-WS 2 has good heat transfer properties in oil, similar to layered graphite [53,54] and carbon nanotubes [55]. IF$\mathrm{WS}_{2}$ /PAO6 can obviously reduce the wear caused by weight loss (the difference between the mass before and after friction), as shown in Figure 13b. Additionally, the weight loss reduced by $87.8 \%$ for the $0.25 \mathrm{wt} \%$ sample. It may be that the oil temperature rises at different rates, which impels different temperatures and wear levels at the same stage.
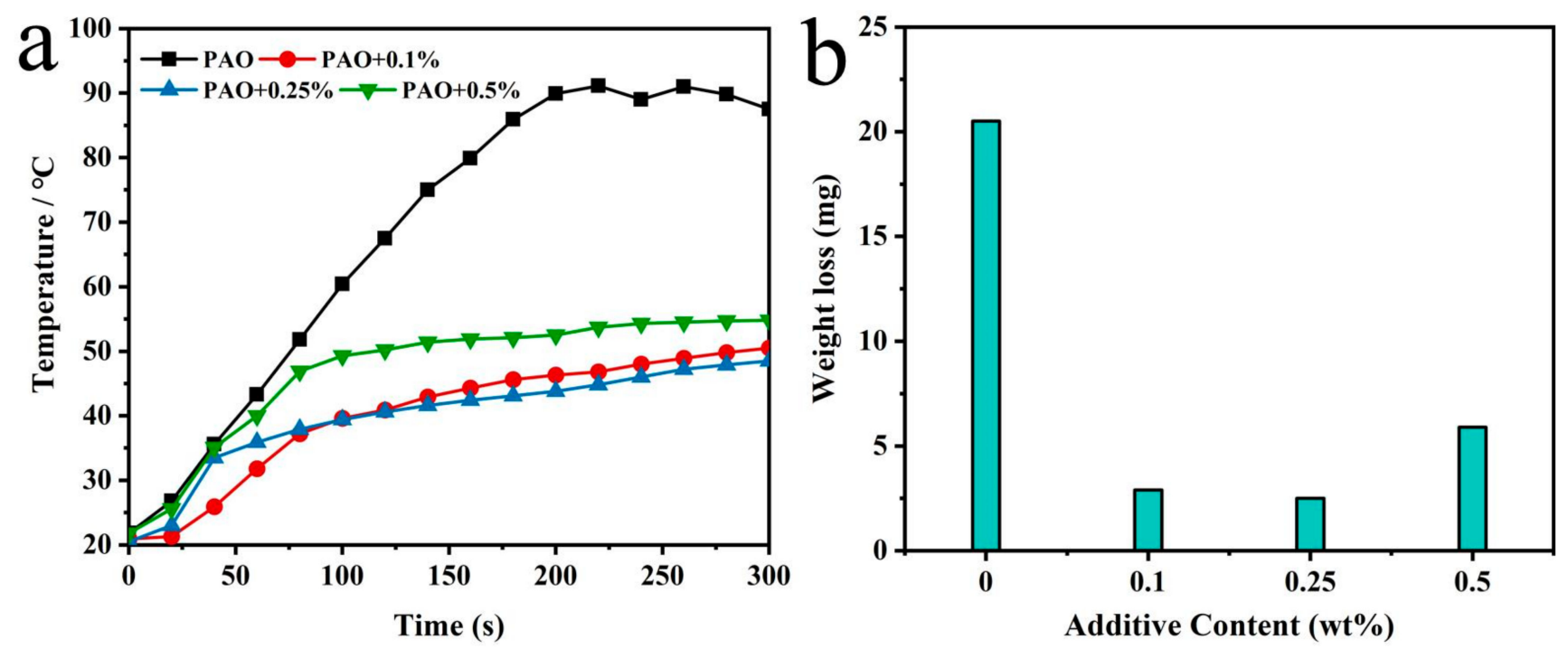

Figure 13. (a) IF-WS 2 with different contents and curve of oil temperature changing with working time. (b) Weight loss profiles (un-constant temperature, load $980 \mathrm{~N}$, working time $5 \mathrm{~min}$ ).

In order to better understand the influence of additives on the physical properties of the PAO6 oil, the dynamic viscosity of lubricating oil before and after the wear experiments was measured, and the results are shown in Figure 14. Before the wear test, with the change 
of temperature, the dynamic viscosity difference of IF-WS 2 /PAO6 with different contents is different, as shown in Table 3. With the increase of additive contents, the difference of dynamic viscosity change is smaller, which illustrates IF-WS ${ }_{2}$ the improved viscositytemperature performance of PAO6. Meanwhile, the dynamic viscosity at $75^{\circ} \mathrm{C}$ and $100{ }^{\circ} \mathrm{C}$ fluctuated around the average values of $10.01 \mathrm{mPa} \cdot \mathrm{s}$ and $6.47 \mathrm{mPa} \cdot \mathrm{s}$, respectively. It should be noted that, due to the existence of dispersant span 80 , the measured value of dynamic viscosity is larger than the standard value. After the friction test, the dynamic viscosity of lubricating oil with different additives has slightly fluctuated at $75^{\circ} \mathrm{C}$, the influence of IF-WS ${ }_{2}$ on viscosity was less than $6.6 \%$. Conversely, the influence of IF-WS 2 on viscosity is less than $2.5 \%$ at $100{ }^{\circ} \mathrm{C}$.

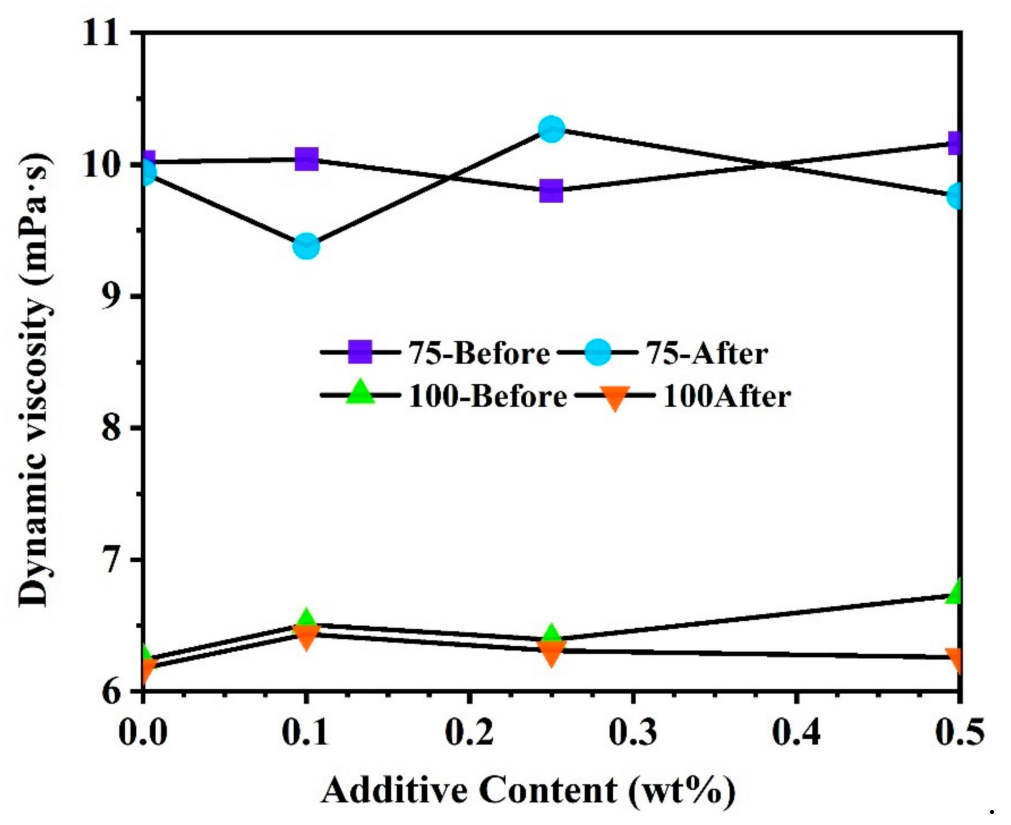

Figure 14. Dynamic viscosities of the oil samples containing different IF-WS $\mathrm{W}_{2}$ additives before and after the wear test at $75^{\circ} \mathrm{C}$ and $100{ }^{\circ} \mathrm{C}$.

Table 3. Dynamic Viscosity and Difference of IF-WS $2 / \mathrm{PAO} 6$ with different content at different temperatures.

\begin{tabular}{ccccc}
\hline & $\mathbf{0} \%$ & $\mathbf{0 . 1} \%$ & $\mathbf{0 . 2 5} \%$ & $\mathbf{0 . 5 \%}$ \\
\hline $75^{\circ} \mathrm{C}$ & $10.02 \mathrm{mPa} \cdot \mathrm{s}$ & $10.04 \mathrm{mPa} \cdot \mathrm{s}$ & $9.8 \mathrm{mPa} \cdot \mathrm{s}$ & $10.16 \mathrm{mPa} \cdot \mathrm{s}$ \\
$100^{\circ} \mathrm{C}$ & $6.24 \mathrm{mPa} \cdot \mathrm{s}$ & $6.51 \mathrm{mPa} \cdot \mathrm{s}$ & $6.39 \mathrm{mPa} \cdot \mathrm{s}$ & $6.75 \mathrm{mPa} \cdot \mathrm{s}$ \\
Differences & $3.78 \mathrm{mPa} \cdot \mathrm{s}$ & $3.53 \mathrm{mPa} \cdot \mathrm{s}$ & $3.41 \mathrm{mPa} \cdot \mathrm{s}$ & $3.41 \mathrm{mPa} \cdot \mathrm{s}$ \\
\hline
\end{tabular}

\section{Conclusions}

In this paper, the behavior and film composition of IF-WS ${ }_{2}$ additives in lubrication were studied. the tribological behavior of IF- $\mathrm{WS}_{2} / \mathrm{PAO} 6$ has been evaluated at two different temperatures, 75 and $100{ }^{\circ} \mathrm{C}$, using a four-ball wear machine. The conclusions are summarized as follows:

(1) At $75^{\circ} \mathrm{C}, \mathrm{IF}-\mathrm{WS}_{2}$ only reduces the friction coefficient, which is not good for anti-wear. At $100{ }^{\circ} \mathrm{C}$, and the effect is bidirectional. At this moment, the optimum addition content is $0.25 \% \mathrm{IF}-\mathrm{WS}_{2}$ particles.

(2) In the friction process, IF-WS 2 particles are transferred and precipitated on the friction surface under the action of high temperature and pressure. IF-WS 2 particles flake off and react chemically with the friction pair matrix to form a chemical film. In addition to the oxide layers $\left(\mathrm{Fe}_{2} \mathrm{O}_{3}, \mathrm{Fe}_{3} \mathrm{O}_{4}, \mathrm{Fe}(\mathrm{OOH}), \mathrm{Fe}_{2}\left(\mathrm{SO}_{4}\right)_{3}\right)$ formed on the friction surface, the newly generated $\mathrm{FeS}_{2}, \mathrm{WS}_{2}$ and $\mathrm{WO}_{3}$ protective films are attached to the friction 
surface of steel balls, hindering the direct contact of friction pairs, the pits and defects caused by the uneven distribution of iron-related oxides are covered by film. Under the combined action of iron oxide and sulfide, the wear performance is improved.

(3) Span 80 makes IF-WS 2 particles uniformly dispersed in PAO6 base oil and effectively improves the dispersion of IF-WS 2 . Under the influence of span 80 dispersant, IF$\mathrm{WS}_{2}$ with the content of $0.1 \%$ has the fastest sedimentation rate, while IF-WS $\mathrm{W}_{2}$ with the content of $0.25 \%$ has better dispersion stability.

(4) The IF-WS 2 additives have shown great influence on the oil temperature raise, and they have effectively reduced and delayed the oil temperature raise, which in turn delay the oxidation of lubricating oil. The addition of IF-WS $\mathrm{Wd}_{2}$ additive improved viscosity-temperature performance of PAO6 lubricating oil. Meanwhile, after the friction test, the influence of IF-WS 2 on dynamic viscosity is less than $6.6 \%$ and $2.5 \%$ at $75^{\circ} \mathrm{C}$ and $100{ }^{\circ} \mathrm{C}$, respectively.

Author Contributions: Conceptualization, W.C.; experiment, W.C., X.C. and G.L.; writing-original draft preparation, W.C., K.T.; Characterization, X.L., L.Z.; funding acquisition, D.C., S.K.T.; Funding, N.W., Y.Z. All authors have read and agreed to the published version of the manuscript.

Funding: This research was funded by the National Nature Science Foundation, grant number 51972068 .

Data Availability Statement: The data presented in this study are available on request from the corresponding author.

Acknowledgments: This work supported by the National Natural Science Foundation (grant NO:51972068) and the Key Laboratory of New Processing Technology for Nonferrous Metals and Materials.

Conflicts of Interest: The authors declare no conflict of interest.

\section{References}

1. Bronshteyn, L.A.; Kreiner, J.H. Energy Efficiency of Industrial Oils. Tribol. Trans. 1999, 42, 771-776. [CrossRef]

2. Boyde, S. Green Lubricants: Environmental Benefits and Impacts on Lubrication. Green Chem. 2002, 4, 293-307. [CrossRef]

3. Guevremont, J.M.; Guinther, G.H.; Szemenyei, D.; Devlin, M.T.; Jao, T.-C.; Jaye, C.; Woicik, J.; Fischer, D.A. Enhancement of Engine Oil Wear and Friction Control Performance through Titanium Additive Chemistry. Tribol. Trans. 2008, 51, 324-331. [CrossRef]

4. Taylor, I.R. Tribology and energy efficiency: From molecules to lubricated contacts to complete machines. Faraday Discuss. 2012, 156, 361. [CrossRef] [PubMed]

5. Zhou, Y.; Qu, J. Ionic Liquids as Lubricant Additives: A Review. ACS Appl. Mater. Interfaces 2016, 9, 3209. [CrossRef]

6. Gusain, R.; Singh, R.; Sivakumar, K.L.N.; Khatri, O.P. Halogen-free imidazolium/ammonium-bis(salicylato)borate ionic liquids as high performance lubricant additives. RSC Adv. 2013, 4, 1293-1301. [CrossRef]

7. Guo, J.; Barber, G.C.; Schall, D.J.; Zou, Q.; Jacob, S.B. Tribological properties of ZnO and $\mathrm{WS}_{2}$ nanofluids using different surfactants. Wear Int. J. Sci. Technol. Frict. Lubr. Wear 2017, 382/383, 8-14.

8. Lu, Z.; Cao, Z.; Hu, E.; Hu, K.; Hu, X. Preparation and tribological properties of $\mathrm{WS}_{2}$ and $\mathrm{WS}_{2} / \mathrm{TiO}_{2}$ nanoparticles. Tribol. Int. 2018, 130, 308-316. [CrossRef]

9. Li, Y.; Lu, H.; Liu, Q.; Qin, L.; Dong, G.J.T.I. A facile method to enhance the tribological performances of MoSe 2 nanoparticles as oil additives. Tribol. Int. 2019, 137, 22-29. [CrossRef]

10. Meng, Y.; Su, F.; Chen, Y. Au/Graphene Oxide Nanocomposite Synthesized in Supercritical $\mathrm{CO}_{2}$ Fluid as Energy Efficient Lubricant Additive. ACS Appl. Mater. Interfaces 2017, 9, 39549-39559. [CrossRef]

11. Wang, L.; Wu, H.; Zhang, D. Synthesis of a novel borate ester containing a phenylboronic group and its tribological properties as an additive in PAO 6 base oil. Tribol. Int. 2018, 121, 21-29. [CrossRef]

12. Peng, S.; Guo, Y.; Xie, G.; Luo, J. Tribological Behavior of Polytetrafluoroethylene Coating Reinforced With Black Phosphorus Nanoparticles. Appl. Surf. Sci. 2018, 441, 670-677. [CrossRef]

13. Borda, F.L.G.; Oliveira, S.J.R.D.; Lazaro, L.M.S.M.; Leiróz, A.J.K. Experimental investigation of the tribological behavior of lubricants with additive containing copper nanoparticles. Tribol. Int. 2017, 117, 52-58. [CrossRef]

14. Xie, H.; Jiang, B.; He, J.; Xia, X.; Pan, F. Lubrication performance of $\mathrm{MoS}_{2}$ and $\mathrm{SiO}_{2}$ nanoparticles as lubricant additives in magnesium alloy-steel contacts. Tribol. Int. 2016, 93, 63-70. [CrossRef]

15. Dan, Z.; Wu, Y.P.; Li, Z.Y.; Cai, Z.B.J.R.A. Tribological properties of $\mathrm{WS}_{2}$ /graphene nanocomposites as lubricating oil additives. RSC Adv. 2017, 7, 14060-14068. 
16. Zhao, J.; He, Y.; Wang, Y.; Wang, W.; Yan, L.; Luo, J. An investigation on the tribological properties of multilayer graphene and MoS2 nanosheets as additives used in hydraulic applications. Tribol. Int. 2016, 97, 14-20. [CrossRef]

17. Kogovek, J.; Kalin, M. Various $\mathrm{MoS}_{2}-$-, $\mathrm{WS}_{2}-$ and C-Based Micro- and Nanoparticles in Boundary Lubrication. Tribol. Lett. 2014, 53, 585-597. [CrossRef]

18. Zhang, X.; Xu, H.; Wang, J.; Ye, X.; Lei, W.; Xue, M.; Tang, H.; Li, C. Synthesis of Ultrathin $\mathrm{WS}_{2}$ Nanosheets and Their Tribological Properties as Lubricant Additives. Nanoscale Res. Lett. 2016, 11, 442. [CrossRef]

19. Abate, F.; D'Agostino, V.; Di Giuda, R.; Senatore, A. Interfaces, Tribological behaviour of $\mathrm{MoS}_{2}$ and inorganic fullerene-like WS 2 nanoparticles under boundary and mixed lubrication regimes. Tribol. Mater.Surf. Interfaces 2010, 4, 91-98. [CrossRef]

20. Xin, Q.; Zhang, S.; Ming, H.; Gao, X.; Sun, J.J.T.I. Tribological properties of $\mathrm{WS}_{2} / \mathrm{MoS}_{2}-\mathrm{Ag}$ composite films lubricated with ionic liquids under vacuum conditions. Tribol. Int. 2017, 115, 389-396.

21. Rabaso, P.; Ville, F.; Dassenoy, F.; Diaby, M.; Mogne, T.L.J.W. Boundary lubrication: Influence of the size and structure of inorganic fullerene-like $\mathrm{MoS}_{2}$ nanoparticles on friction and wear reduction. Wear 2014, 320, 161-178. [CrossRef]

22. Liu, L.; Zhou, W. MoS 2 hollow microspheres used as a green lubricating additive for liquid paraffin. Tribol. Int. 2017, 114, 315-321. [CrossRef]

23. Rapoport, L.; Bilik, Y.; Feldman, Y.; Homyonfer, M.; Cohen, S.R.; Tenne, R. Hollow nanoparticles of $\mathrm{WS}_{2}$ as potential solid-state lubricants. Nature 1997, 387, 791-793. [CrossRef]

24. Rapoport, L.; Leshchinsky, V.; Lapsker, I.; Volovik, Y.; Nepomnyashchy, O.; Lvovsky, M.; Popovitz-Biro, R.; Feldman, Y.; Tenne, R. Tribological properties of $\mathrm{WS}_{2}$ nanoparticles under mixed lubrication. Wear 2003, 255, 785-793. [CrossRef]

25. Rapoport, L.; Feldman, Y.; Homyonfer, M.; Cohen, H.; Sloan, J.; Hutchison, J.L.; Tenne, R. Inorganic fullerene-like material as additives to lubricants: Structure-function relationship. Wear 1999, 225-229, 975-982. [CrossRef]

26. Joly-Pottuz, L.; Dassenoy, F.; Belin, M.; Vacher, B.; Martin, J.M.; Fleischer, N. Ultralow-friction and wear properties of IF-WS 2 under boundary lubrication. Tribol. Lett. 2005, 18, 477-485. [CrossRef]

27. Aldana, P.U.; Dassenoy, F.; Vacher, B.; Le Mogne, T.; Thiebaut, B. Fabrice, $\mathrm{WS}_{2}$ nanoparticles anti-wear and friction reducing properties on rough surfaces in the presence of ZDDP additive. Tribol. Int. 2016, 102, 213-221. [CrossRef]

28. Ratoi, M.; Niste, V.B.; Zekonyte, J. WS 2 nanoparticles-Potential replacement for ZDDP and friction modifier additives. RSC Adv. 2014, 4, 21238-21245. [CrossRef]

29. Moshkovith, A.; Perfiliev, V.; Lapsker, I.; Fleischer, N.; Tenne, R.; Rapoport, L. Friction of Fullerene-Like WS2 Nanoparticles: Effect of Agglomeration. Tribol. Lett. 2006, 24, 225-228. [CrossRef]

30. Yang, H.; Liu, S.; Li, J.; Li, M.; Peng, G.; Zou, G. Synthesis of inorganic fullerene-like WS2 nanoparticles and their lubricating performance. Nanotechnology 2006, 17, 1512. [CrossRef]

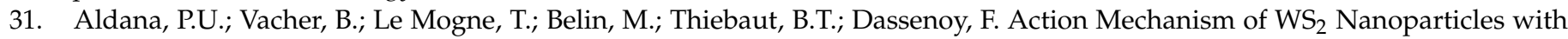
ZDDP Additive in Boundary Lubrication Regime. Tribol. Lett. 2014, 56, 249-258. [CrossRef]

32. Xu, F.; Wang, N.; Chang, H.; Xia, Y.; Zhu, Y. Continuous Production of IF-WS 2 Nanoparticles by a Rotary Process. Inorganics 2014, 2, 313-333. [CrossRef]

33. Feldman, Y.; Frey, G.L.; Homyonfer, M.; Lyakhovitskaya, V.; Margulis, L.; Cohen, H.; Hodes, G.; Tenne, R.; Hutchison, J.L. Bulk synthesis of inorganic fullerene-like $\mathrm{MS}_{2}(\mathrm{M}=\mathrm{Mo}, \mathrm{W})$ from the respective trioxides and the reaction mechanism. Cheminform 1996, 27, 5362-5367.

34. Feldman, Y.; Wasserman, E.; Srolovitz, D.J.; Tenne, R.J.S. High-Rate, Gas-Phase Growth of $\mathrm{MoS}_{2}$ Nested Inorganic Fullerenes and Nanotubes. Science 1995, 267, 222-225. [CrossRef]

35. Ghorai, A.; Bayan, S.; Gogurla, N.; Midya, A.; Ray, S.K. Highly Luminescent $\mathrm{WS}_{2}$ Quantum Dots/ZnO Heterojunctions for Light Emitting Devices. Tribol. Mater. Surf. Interfaces 2016, 9, 558-565. [CrossRef]

36. Aldana, P.U.; Dassenoy, F.; Vacher, B.; Le Mogne, T.; Thiebaut, B.T.; Bouffet, A. Anti spalling effect of WS 2 nanoparticles on the lubrication of automotive gearboxes. Tribol. Trans. 2015, 29, 178-188.

37. Wu, N.; Hu, N.; Zhou, G.; Wu, J. Tribological properties of lubricating oil with micro/nano-scale WS 2 particles. J. Exp. Nanosci. 2018, 13, 1-12. [CrossRef]

38. Zhang, R.; Qiao, D.; Liu, X.; Guo, Z.; Cai, M.; Shi, L.J.T.I. A facile and effective method to improve the dispersibility of WS 2 nanosheets in PAO8 for the tribological performances. Tribol. Int. 2017, 118, 60-70. [CrossRef]

39. Gulzar, M.; Masjuki, H.H.; Kalam, M.A.; Varman, M.; Zulkifli, N.W.M.; Mufti, R.A.; Zahid, R. Tribological performance of nanoparticles as lubricating oil additives. J. Nanoparticle Res. 2016, 18, 223. [CrossRef]

40. Joly-Pottuz, L.; Martin, J.M.; Dassenoy, F.; Belin, M.; Montagnac, G.; Reynard, B.; Fleischer, N. Pressure-induced exfoliation of inorganic fullerene-like $\mathrm{WS}_{2}$ particles in a Hertzian contact. J. Appl. Phys. 2006, 99, 023524. [CrossRef]

41. Gustavsson, F.; Jacobson, S.J.T.I. Diverse mechanisms of friction induced self-organisation into a low-friction material-an overview of $\mathrm{WS}_{2}$ tribofilm formation. Tribol. Int. 2016, 101, 340-347. [CrossRef]

42. Maharaj, D.; Bhushan, B. Effect of $\mathrm{MoS}_{2}$ and $\mathrm{WS}_{2}$ Nanotubes on Nanofriction and Wear Reduction in Dry and Liquid Environments. Tribol. Lett. 2013, 49, 323-339. [CrossRef]

43. Wu, X.; Gong, K.; Zhao, G.; Lou, W.; Wang, X.; Liu, W. $\mathrm{MoS}_{2} / \mathrm{WS}_{2}$ Quantum Dots as High-Performance Lubricant Additive in Polyalkylene Glycol for Steel/Steel Contact at Elevated Temperature. Adv. Mater. Interfaces 2018, 5, 1700859. [CrossRef]

44. Lin, W.T.; An, C. Abrasion Resistance of Cement-Based Composites. In Abrasion Resistance of Materials; Marcin, A., Ed.; InTech: Rijeka, Croatia, 2012. 
45. Zhang, W.; Zhou, M.; Zhu, H.; Tian, Y.; Wang, K.; Wei, J.; Ji, F.; Li, X.; Li, Z.; Zhang, P. Tribological properties of oleic acid-modified graphene as lubricant oil additives. J. Phys. D Appl. Phys. 2011, 44, 205303. [CrossRef]

46. Song, W.; Yan, J.; Ji, H. Fabrication of GNS/MoS2 composite with different morphology and its tribological performance as a lubricant additive. Appl. Surf. Sci. 2019, 469, 226-235. [CrossRef]

47. Wu, Z.; Wang, D.; Wang, Y.; Sun, A. Preparation and Tribological Properties of $\mathrm{MoS}_{2}$ Nanosheets. Adv. Eng. Mater. 2010, 12, 534-538. [CrossRef]

48. Tenne, R.; Homyonfer, M.; Feldman, Y. Nanoparticles of Layered Compounds with Hollow Cage Structures (Inorganic FullereneLike Structures). Chem. Mater. 1998, 10, 3225-3238. [CrossRef]

49. Xu, Y.; Geng, J.; Peng, Y.; Liu, Z.; Yu, J.; Hu, X.J. Lubricating mechanism of $\mathrm{Fe}_{3} \mathrm{O}_{4} @ \mathrm{MoS}_{2}$ core-shell nanocomposites as oil additives for steel/steel contact. Tribol. Int. 2018, 121, 241-251. [CrossRef]

50. Niste, V.B.; Ratoi, M.; Tanaka, H.; Xu, F.; Zhu, Y.; Sugimura, J. Self-lubricating Al-WS ${ }_{2}$ composites for efficient and greener tribological parts. Sci. Rep. 2017, 7, 14665. [CrossRef]

51. Xie, F.; Ge, S.; Li, X.; Hao, J. Influence of Surfactants on the Dispersion Stability of Nano-graphite in the Lubricating Oil. Lubr. Eng. 2012, 37, 1-5.

52. Liu, Z.C. Reason for Aggregation of Nanoparticles in Nano-materials and Solutions. Value Eng. 2017, 13, $157-158$.

53. Zhang, L.-X.; Teng, D.; Wu, Y.-H.; Wang, L.-Y.; Song, D.-P. Mechanism of graphene lubricating oil cooling effect on $\mathrm{Si}_{3} \mathrm{~N}_{4}-\mathrm{GCr}_{15}$ friction pair. Heat Mass Transfer. 2020, 56, 2273-2283. [CrossRef]

54. Prasad, B.K. Lubricated Sliding Wear Behavior of a Cast Iron: Effect of Graphite and/or Talc Fraction in Oil. J. Mater. Eng. Perform. 2010, 19, 413-420. [CrossRef]

55. Khalil, W.; Mohamed, A.; Bayoumi, M.; Osman, T.A. Tribological properties of dispersed carbon nanotubes in lubricant. Fuller. Nanotub. Carbon Nanostruct. 2016, 24, 479-485. [CrossRef] 